Geosciences Journal

\title{
FRACTAL ANALYSIS AND STATISTICS OF SEISMIC GENERATION RATES: AN EXAMPLE FOR THE SOUTHERN CALIFORNIA \\ --Manuscript Draft--
}

\begin{tabular}{|c|c|}
\hline Manuscript Number: & GEOJ-D-16-00066 \\
\hline Full Title: & $\begin{array}{l}\text { FRACTAL ANALYSIS AND STATISTICS OF SEISMIC GENERATION RATES: AN } \\
\text { EXAMPLE FOR THE SOUTHERN CALIFORNIA }\end{array}$ \\
\hline Article Type: & Article \\
\hline Corresponding Author: & $\begin{array}{l}\text { Xavier Lana, PhD } \\
\text { Univ. Politècnica Catalunya } \\
\text { Barcelona, Catalunya SPAIN }\end{array}$ \\
\hline \multicolumn{2}{|l|}{$\begin{array}{l}\text { Corresponding Author Secondary } \\
\text { Information: }\end{array}$} \\
\hline Corresponding Author's Institution: & Univ. Politècnica Catalunya \\
\hline \multicolumn{2}{|l|}{$\begin{array}{l}\text { Corresponding Author's Secondary } \\
\text { Institution: }\end{array}$} \\
\hline First Author: & Xavier Lana, PhD \\
\hline \multicolumn{2}{|l|}{ First Author Secondary Information: } \\
\hline \multirow[t]{4}{*}{ Order of Authors: } & Xavier Lana, PhD \\
\hline & Dolors Martínez, Professor \\
\hline & Carina Serra, Professor \\
\hline & Seyed Amir Hosseini, PhD Student \\
\hline \multicolumn{2}{|c|}{ Order of Authors Secondary Information: } \\
\hline \multicolumn{2}{|l|}{ Funding Information: } \\
\hline Abstract: & $\begin{array}{l}\text { The seismic generation rate, SGR, at Southern California along the } 1981-2007 \\
\text { recording period is analysed with the main purpose of finding out whether there exist } \\
\text { some correlations between seismic activity before, after and along aftershock } \\
\text { sequences triggered by mainshocks of high magnitude. The possibility that a } \\
\text { mainshock could be triggered by another neighbouring mainshock and its aftershock } \\
\text { sequence is also investigated. The analyses are based on monthly SGR series, } \\
\text { obtained as the number of events detected every month along the recording period } \\
\text { considered. These monthly SGR series are derived for three aftershock areas } \\
\text { associated with Landers (June } 28,1992, M w=7.3 \text { ), Northridge (January } 17,1994, \mathrm{Mw} \\
=6.7 \text { ) and Hector Mine (October 16,1999, Mw }=7.1 \text { ) mainshocks. The most relevant } \\
\text { features of SGR series are investigated through various techniques: } 1 \text { ) the rescaled } \\
\text { range analysis and the interpretation of the Hurst exponent in terms of persistence, } \\
\text { anti-persistence and randomness; } 2 \text { ) time trend estimation by the Kendall-tau algorithm } \\
\text { and assessment of their statistical significance by the Mann-Kendall test; 3) the self- } \\
\text { affine character, derived from semivariograms, and the Hausdorff measure; } 4 \text { ) } \\
\text { autocorrelation and power spectra; } 5 \text { ) cross-correlation and cross-power spectra; } 6 \text { ) } \\
\text { the search for the statistical distribution best reproducing the empirical probability of } \\
\text { SGR series. Additionally, a close look at plots of epicenters within the aftershock areas, } \\
\text { distinguishing between periods of background and aftershock activity, permits } \\
\text { detecting some features of the seismicity. Changes on spatial patterns of seismicity } \\
\text { suggest that the effects of tectonic stress redistribution could persist beyond an } \\
\text { aftershock period, at short and medium distances of the mainshock. This possibility } \\
\text { would be also in agreement with cross-correlation results for SGR series. }\end{array}$ \\
\hline Suggested Reviewers: & $\begin{array}{l}\text { Jaume Pous, PhD } \\
\text { Full Professor in Geophysics, Universitat de Barcelona } \\
\text { jpous@ub.edu } \\
\text { Expert in geophysics }\end{array}$ \\
\hline
\end{tabular}


Antonio Posadas, PhD

Full Professor, Universidad de Almeria

aposadas@ual.es

Specialist in nonlinear complex mechanisms as the case of seismicity series

Eléonore Sttutzmann, PhD

Chief of Seismology, IPG Paris, Institute du Physique du Globe de Paris

stutz@ipg.fr

Great experience in seismology 


\section{Fractal analysis and statistics of seismic generation rates: the} example of the Southern California

Xavier Lana ${ }^{(1)}$, Maria Dolors Martínez ${ }^{(1)}$, Seyed Amir Hosseini(1), Carina Serra ${ }^{(1)}$

(1) Departament de Física, Universitat Politècnica de Catalunya, Barcelona. Av. Diagonal 647-649, E-08028 Barcelona, Spain

Corresponding autor: Xavier Lana,

e-mail adress: francisco.javier.lana@upc.edu

Fax-number : +0034-93401183

Phone-number: +0034-934010825

Runnig title: Sesimic generation rate and fractality 
1 ABSTRACT. The seismic generation rate, SGR, at Southern California along the 1981-2007

2 recording period is analysed with the main purpose of finding out whether there exist some

3 correlations between seismic activity before, after and along aftershock sequences triggered

4 by mainshocks of high magnitude. The possibility that a mainshock could be triggered by

5 another neighbouring mainshock and its aftershock sequence is also investigated. The

6 analyses are based on monthly SGR series, obtained as the number of events detected every

7 month along the recording period considered. These monthly SGR series are derived for three

8 aftershock areas associated with Landers (June 28, 1992, Mw = 7.3), Northridge (January 17,

9 1994, Mw = 6.7) and Hector Mine (October 16, 1999, Mw = 7.1) mainshocks. The most

10 relevant features of SGR series are investigated through various techniques: 1) the rescaled

11 range analysis and the interpretation of the Hurst exponent in terms of persistence, antipersistence and randomness; 2) time trend estimation by the Kendall-tau algorithm and assessment of their statistical significance by the Mann-Kendall test; 3) the self-affine character, derived from semivariograms, and the Hausdorff measure; 4) autocorrelation and power spectra; 5) cross-correlation and cross-power spectra; 6) the search for the statistical distribution best reproducing the empirical probability of SGR series. Additionally, a close look at plots of epicenters within the aftershock areas, distinguishing between periods of background and aftershock activity, permits detecting some features of the seismicity. Changes on spatial patterns of seismicity suggest that the effects of tectonic stress redistribution could persist beyond an aftershock period, at short and medium distances of the mainshock. This possibility would be also in agreement with cross-correlation results for SGR series.

Keywords: seismic generation rate, southern California, fractal analyses, power and crosspower spectra, generalized logistic distribution. 


\section{INTRODUCTION}

The analysis of the background seismic activity could represent a significant contribution to a better understanding of the complex mechanism of earthquake generation.

Precursory seismic quiescence, several aspects of seismic hazard and correlations between aftershock sequences and seismic activity can be analyzed by taking into account background seismicity. Attention has been devoted to these topics for the last decades (Habermann and Wyss, 1984; Eneva and Paulis, 1991; Cao et al., 1996; Michael and Jones, 1998; Myers and

(2011); among others). Another point of view consists in identifying changes on seismicity just before a large earthquake, as proposed by Shcherbakov et al. (2006), by using the twopoint correlation function and the correlation length concept. A contribution to the identification of aftershock sequences, based on the analysis of background seismicity, should be also mentioned (Bottiglieri et al., 2009). These authors proposed a method for distinguishing between Poissonian independent events and aftershocks by means of a variation coefficient related to the elapsed time between consecutive earthquakes. Another point of view is offered by Console et al. (2010), who proposed a declustering of seismic catalogues based on the ETAS model.

The objectives and methodology of the present study are quite different. They are based on the seismic generation rate, SGR, series, which are obtained as the number of events detected every month. The monthly scale permits generating long SGR series and, at the same time, to obtain representative rates. This basic definition involves pure background activity, aftershock periods and seismic activity influenced by neighboring active seismic areas. The parameters used to describe the most relevant features of SGR series are based on the 
following computational methods. First, two algorithms for computing time trends in SGR series and assessing their statistical significance; second, auto- and cross-correlation, and the corresponding power- and cross-power spectra, to detect spectral contents of SGR series; third, a preliminary fractal study based on the rescaled range analysis and the interpretation of the Hurst exponent in terms of persistence, anti-persistence or randomness. Additionally, the self-affine character of the series, being characterized by the Hausdorff measure; and finally, the statistical description of SGR in terms of the three-parameter generalized logistic, GLO, distribution and the L-moments formulation.

Two types of SGR series are generated, according to the different objectives established. The first type of series, SGR1, is computed along all the recording period, thus including background seismicity, main events and aftershock activity. SGR1 consists of three series, each of them corresponding to the aftershock spatial domains associated with Landers (June 28, 1992, Mw = 7.3), Northridge (January 17, 1994, Mw = 6.7) and Hector Mine (October 16, 1999, Mw = 7.1) mainshocks. The second type of series, SGR2, also consists of three series, computed for the same spatial domains as SGR1, assembling only periods of background seismic activity, which have been selected considering some seismic generation rate profiles, as will be explained in the next Section. SGR1 permits detecting the interaction of background seismicity, mainshocks and their aftershock sequences at short and medium distances within a seismic area. SGR2 is considered to strictly obtain information on background seismicity patterns before and after seismic crises generated by mainshocks.

\section{DATABASE}

The SGR series are obtained from the seismic records of the Southern California Seismic Network, SCSN, catalog, which is available at http://www.dat.scec.org/ftp/catalogs/SCSN. 
This seismic network covers the area given by coordinates $32^{\circ} \mathrm{N}-37^{\circ} \mathrm{N}$ and $122^{\circ} \mathrm{W}-114^{\circ}$ W. The recording period analyzed spans from 1981 to 2007 . Within this period, three relevant aftershock sequences have occurred, related to Landers (June 28, 1992, Mw = 7.3), Northridge (January 17, 1994, Mw = 6.7) and Hector Mine (October 16, 1999, Mw = 7.1) mainshocks. Figure 1a depicts the geographical location of the SCSN stations. Figure 1b shows the seismic activity $(\mathrm{m} \geq 4.5)$ in this area along the $1981-2007$ recording period. The fit to the Gutenberg-Richter law is assessed for this period and the spatial domains corresponding to Landers, Northridge and Hector Mine aftershock sequences (Woessner and Wiemer, 2005), and almost equal minimum magnitudes of completeness are obtained $(\mathrm{m}=$ 1.5 - 2.0), as shown in Figure 1c. Table 1 summarizes the main characteristics of the three seismic crises, according to Shcherbakov et al. (2006), and aftershock spatial domains as determined by Kagan (2002). It is worth mentioning that Shcherbakov et al. (2006) deduce that the catalogue completeness of the three aftershock series is achieved by a minimum local magnitude of 2.0, very close to that obtained when the whole 1981-2007 recording period is considered. Consequently, to prevent some inconsistency or lack of completeness on the series, both SGR1 and SGR2 are generated taking as minimum local magnitude 2.0. It can be also noted that Landers and Hector Mine aftershock areas partially overlap, whereas Northridge aftershock area has no spatial intersection with the other two. (Figures 1a, 1b, 1c about here) (Table 1 about here)

Figures 2a-2c show the SGR1 series for the three aftershock domains. Whereas SGR1 for Northridge area is free of remarkable disturbances due to other seismic crises at short, medium or large distances, the interaction between Landers and Hector Mine areas is quite evident. These profiles are used to establish the time intervals of background seismicity for generating the SGR2 series for each aftershock area. Additionally, it is worthy of mention the 
sharp increase of the background seismicity rate a few months before Landers mainshock, which could be taken as some premonitory sign of the seismic crisis. Although Landers and Hector Mine aftershock areas partially overlap, for the latter this behavior is not so clearly observed. No signs of such pattern are detected for Northridge area. It is also remarkable the increase of the background seismicity rate beyond Landers aftershock period in comparison with that previous to the mainshock. This fact would indicate that, in spite of the seismic activity decay along the aftershock period (Omori's law), the stationary state of stresses would differ from that previous to the mainshock. A very similar pattern is observed for Northridge area. Such behavior is quite different before and after Hector Mine crisis because of the perturbation generated in this area by Landers crisis. Whereas the background rate diminishes beyond Hector Mine crisis when comparing with that previous to the mainshock, it is essentially similar to that previous to Landers mainshock. (Figures 2a, 2b about here)

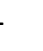

The interaction between Landers and Hector Mine areas is illustrated in the maps of Figure 3. These maps represent sequentially seven periods corresponding to: background seismicity; the possible influence of two events of moderate magnitude $\left(\mathrm{M}_{\mathrm{W}}=5.5,5.7\right)$ in this area; another period of background seismicity; the influence of Landers mainshock $\left(\mathrm{Mw}_{\mathrm{w}}=\right.$ 7.3) and its aftershock sequence; another period of background seismicity; Hector Mine ( $\mathrm{M}_{\mathrm{w}}$ = 7.1) mainshock and its aftershock sequence; and, finally, the last period of background seismicity. A common feature to all maps is an area of persistent background and aftershock activity, approximately delimited by latitudes $34.5^{\circ}-35.5^{\circ} \mathrm{N}$ and longitudes $117.3^{\circ}-116.5^{\circ}$ W. After the two events of moderate magnitude $\left(\mathrm{Mw}_{\mathrm{w}}=5.5,5.7\right)$, the spatial patterns of seismicity do not remarkably change. Nevertheless, the effects of Landers mainshock and its aftershock sequence are manifested in a new fringe of seismic activity, detected not only during the aftershock period of Landers but also along the following background activity. 
Signs of this new fringe are also detected along the Hector Mine mainshock and its aftershock period, as well as in the background activity after Hector Mine crisis. Additionally, the nucleus of seismic activity during the Hector Mine crisis is also detected along the posterior background activity. The influence of Landers crisis on posterior seismic patterns could be explained remembering that Landers aftershock area partially overlaps that of Hector Mine. Nevertheless, a relatively surprising fact is that Landers mainshock occurred seven years before Hector Mine event, this time span notably exceeding the assumed one-year duration of Landers aftershock sequence. In short, there would be evidences that Landers seismic crisis triggered Hector Mine mainshock. (Figure 3 about here)

Maps of Figure 4 represent the spatial distribution of seismic activity in Northridge aftershock area for the whole recording period and for three sequential periods distinguishing background and aftershock activities. Northridge area is characterized by an activity lower than that of Landers and Hector Mine. The spatial distribution of background seismicity is quite similar before and after the mainshock (January 17, 1994) and the aftershock activity is strongly concentrated within an area of coordinates $34.1^{\circ}-34.5^{\circ} \mathrm{N}$ and $118.6^{\circ}-118.9^{\circ} \mathrm{W}$. As suggested by Figure 2b, seismicity patterns seem not to be governed by Landers crisis.

(Graphs of Figure 4 about here)

\section{METHODOLOGY OF ANALYSIS}

\subsection{Rescaled-range Analysis}

The rescaled-range analysis (Korvin,1992; Goltz, 1997; Diks, 1999, among others) is based on the power-law

$R(\tau) / S(\tau) \propto \tau^{H}$ 
$148 \mathrm{R}(\tau)$ and $\mathrm{S}(\tau)$ are, respectively, the range of variation and standard deviation of time series 149 segments of length $\tau$, the exponent of this power-law being the Hurst exponent, $H$. If empiric data fit well equation (1), there is a clear sign that the series behaves as a self-similar or self-

151 affine fractal. Additionally, the Hurst exponent, depending on the range of values, offers a 152 description of the randomness $(\mathrm{H} \approx 0.5)$, persistence $(\mathrm{H}>0.5)$ or anti-persistence $(\mathrm{H}<0.5)$ of the time series. This qualification represents a first step in the prediction of forthcoming elements (seismic generation rates) of the series. Essentially, randomness would discard successful forecasting methods, whereas persistence and anti-persistence would suggest specific forecasting strategies. Time trends would be an interesting predictive tool in case of persistence. For anti-persistent series, an average of previous elements would be the appropriate way. The rescaled analysis is applied to: 1) the three SGR1 series; 2) the different segments of SGR2 series, corresponding to periods of background activity, delimited according to Figures 2,3 and 4 .

\subsection{Hausdorff Measure}

Whereas the rescaled range analysis gives some insight about the possible self-similar fractal behavior of SGR series, the semivariogram

$165 \gamma(\xi)=\frac{1}{2(N-\xi)} \sum_{n=1}^{N-\xi}\left(y_{n+\xi}-y_{n}\right)^{2}$

with $\xi$ the different lags and $\mathrm{N}$ the whole length of the series $\left\{y_{n}\right\}$, permits investigating if these series behave like self-affine fractals. If the semivariogram fit to a power-law, it is assumed that the series is self-affine and $\gamma(\xi)$ behaves like $\xi^{2 \mathrm{Ha}}$ (Turcotte, 1997, Malamud and Turcotte, 1999) with Ha the Hausdorff measure, which is defined within the $(0,1)$ range. 


\subsection{Time Trends}

Evaluation of time trends and their statistical significance is a well-developed field, with wide application on climatic change assessments, and straightforward application to other scientific fields. It is usually recommended the estimation of time trends by means of the Kendall-tau method (Kunkel et al., 1999; Zhang et al., 2004), instead of a simple linear regression of data, provided that series to be analyzed are long enough. In this way, the finally chosen trend becomes the most probable, among all possible estimations. Statistical significance of time trends could be based on Monte-Carlo simulations (Zhang et al., 2004; Serra et al., 2006). Nevertheless, it is quite usual the application of analytical methods as the Spearmann or the Mann-Kendall tests (Sneyers, 1990; Mitchell et al., 1966) to assess at 95$99 \%$ the statistical significance of the computed trends. This type of analysis is applied to series SGR2.

\subsection{Power- and Cross-power Spectral Densities}

An additional contribution to the description of the background seismicity is offered by auto- and cross-correlation and the corresponding power- and cross-power spectral densities. The analysis of the autocorrelation function permits to determine if series are shortor long- range persistent (anti-persistent) or to confirm their randomness. In this way, it represents an additional contribution to seismic rate description. Power spectral density permits to determine relevant periodicities of the analyzed signal by contrasting them with white- and Markovian red-noise components (Lana and Burgueño, 2000; Lana et al., 2005). Moreover, it can be also verified if the spectral content $S(\omega)$ decays as

$S(\omega) \propto \omega^{-\beta}$, 
the exponent $\beta$ being a measure of strong or weak persistence (anti-persisitence). Cross-

correlation permits to detect links between different series and the delay among them. Bearing

197 in mind the necessity of long SGR series to obtain confident auto(cross) correlation and

198 spectral contents, only SGR1 series, covering the whole recording period, are considered at 199 this step of the analysis. Taking advantage of results obtained for Hurst exponent and 200 Haussdorff measure and relationships among them and $\beta$ exponent (Turcotte, 1997), different 201 models (pure Gaussian noise or a variety of fractal Gaussian noise and fractal Brownian 202 walks) can be assumed for the evolution of the seismic generation rate. For series SGR1 203 including all seismic activity, the three parameters $(\mathrm{H}, \mathrm{Ha}$ and $\beta)$ are determined from empiric 204 data. For series SGR2 restricted to pure background seismic activity, it is very likely a notable lack of accuracy on the spectral contents due to the relatively short length of the series. In this case, $\beta$ parameters can be inferred from relationships established between pairs $(H, \beta)$ and $(\mathrm{Ha}, \beta)$ under two assumptions. First, SGR2 series are self-affine fractals; second, they can be assimilated to fractional Gaussian noise or Brownian walks.

\subsection{Statistical Model for SGR Series}

211

A statistical description of SGR series is achieved by means of the L-moments 212 formulation (Hosking and Wallis, 2005) and the generalized logistic distribution, GLO. The 213 probability density function of GLO is given by

$214 f(x)=\alpha^{-1} e^{-(1-\kappa) Y} /\left\{1+e^{-Y}\right\}^{2}$,

215

$Y=-\kappa^{-1} \log \{1-\kappa(x-\xi) / \alpha\} ; \kappa \neq 0$,

216 $Y=(x-\xi) / \alpha ; \kappa=0$, 
and $\xi, \alpha$ and $\kappa$ the location, scale and shape parameters of the distribution respectively. These

218

219

220

221

222

223

224

225

226

227

228

229

230

231

232

233

234

235

236

237

238

239

240

parameters are derived from the first, $\lambda_{1}$, and second, $\lambda_{2}$, L-moments and the L-skewness, $\tau_{3}$, defined as the quotient $\lambda_{3} / \lambda_{2}$, being $\lambda_{3}$ the third L-moment

$\kappa=-\tau_{3}$,

$\alpha=\left\{\lambda_{2} \sin (\pi \kappa)\right\} /(\pi \kappa)$,

$\xi=\lambda_{1}-\alpha_{\{}\{1 / \kappa-\pi / \sin (\pi \kappa)\}$

For negative values of the shape parameter, the argument $x$ of the GLO distribution is defined within the interval $(\xi+\alpha / \kappa \leq \mathrm{x}<\infty)$. As aftershock activity is characterized by high rates for a short time after the mainshock, and null rates at monthly scale are very unlikely, the range of the argument $x$, for negative $\kappa$ and positive $\xi+\alpha / \kappa$, should be appropriate.

228

To guarantee a reliable estimation of empiric L-moments and narrow uncertainty bands derived from the Kolmogorov-Smirnov test (Benjamin and Cornell, 1970), long series are recommended. Consequently, from the statistical point of view, the seismic generation rate is analyzed for SGR1 series covering the whole recording period, thus including background seismicity and large events and their associated aftershock activity. Additionally, new series, generated by assembling SGR2 periods of background seismicity, is also fitted to the same GLO distribution.

\section{RESULTS}

\subsection{Rescaled-range Analysis and Hurst Exponent}

The results of the rescaled analysis for the aftershock areas of Landers, Northridge and Hector Mine mainshocks are obtained making distinction among the whole 1981-2007 recording period and time intervals of background seismicity. Figure 5 shows the fit of the 
rescaled analysis to a power-law for SGR1 series, from which Hurst exponents can be

242 determined, with a good square regression coefficient, greater than 0.99. Clear signs of 243 persistence are observed for this period, as $\mathrm{H}$ exceeds 0.78 in all cases. Table 2 lists the Hurst 244 exponent values derived for several background seismicity periods in the three aftershock 245 areas (series SGR2). Persistence is also evident, especially for some periods in Landers and 246 Hector Mine areas, with $\mathrm{H}$ exceeding 0.90. Although these almost coincident aftershock areas 247 show similar seismicity patterns and there are some evidences of Landers crisis triggering 248 Hector Mine mainshock, the same segments of background activity do not always show very 249 similar Hurst exponents. In fact, whereas in Landers area Hurst exponent decreases along 250 consecutive background seismicity periods, the opposite tendency is observed for Hector 251 Mine area, as also in Northridge area. It is worth mentioning that the sign of these tendencies is kept although these background seismicity periods are interrupted by the mainshocks and their aftershock sequences. Whereas the increase on $\mathrm{H}$ values before and after a seismic crisis is remarkable for Hector Mine and Northridge areas, the decrease in Landers area is notably smaller. Although only three examples are shown here, it seems to be possible that $\mathrm{H}$ would be a fractal parameter influenced by stress field redistribution after a mainshock and its aftershock activity. (Figure 5 and Table 2 about here)

\subsection{Time Trends}

As mentioned before, one complement to the rescaled analysis, especially when persistence is established, is the quantification of time trends and their statistical significance. Table 3 summarizes the results in the three aftershock areas, for the segments of background activity listed in Table 2. It should be remembered the partial overlapping of Landers and Hector Mine areas. Consequently, similar patterns are expected for both areas. For most of the analyzed periods, statistically significant trends are found. A detailed revision of trend signs 
and statistical significance suggests: 1) for periods previous to seismic crises linked to

267 moderate magnitude mainshocks (1981-1986/1987), positive or non significant trends are

268

269

270

271

272

273

274

275

276

277

278

279

280

281

282

283

284

285

286

287

288

289

detected; 2) along some years before aftershock sequences of Landers (1992) and Northridge (1994), associated with high magnitude mainshocks, clearly significant negative trends on background seismicity are established. This feature cannot be corroborated for Hector Mine crisis (1999), because no significant trends are determined for the previous period (19961999); 3) once the stress release process linked to Northridge and Hector Mine crises can be assumed as finished, significant negative trends are detected. This pattern cannot be assessed for Landers crisis, as significant trends are not found. (Table 3 about here)

\subsection{Self-affine Character}

The fractal behavior, and more specifically the self-affine character, of the SGR series can be also analyzed by means of semivariograms. As mentioned, if a semivariogram $\gamma(\zeta)$ behaves as $\zeta^{2 \mathrm{Ha}}$, being $\zeta$ the lag in time units of months, the Hausdorff measure, Ha, can be easily estimated. As shown in Figure 6, such a behavior is detected for series SGR1. Hausdorff measure varies within a narrow range from 0.88 to 0.93 . In agreement with relationships established by Turcotte (1997) between Hausdorff measure, Hurst exponent and the parameter $\beta$ of the power spectral density $S(\omega)$, proportional to $\omega^{-\beta}$, SGR1 series could be similar to two different types of self-affine sets. After generating series of Gaussian noise, computing their Fourier transform, filtering the obtained spectra and, finally, applying an inverse Fourier transform (Mandelbrot and Wallis, 1969), different self-affine series are obtained, depending on the filtering parameter $\beta / 2$. From the point of view of Hausdorff measure, SGR1 would be summed fractional Brownian walks (sfBw) with $\beta$ ranging approximately from 2 to 3 . By taking into account Hurst values, SGR1 would be fractional 
Gaussian noises (fGn) with $\beta$ within the $\{0,1\}$ range. Although the self-affine character of

291

292

293

294

295

296

297

298

299

300

301

302

303

304

305

306

307

308

309

310

311

312

313

SGR1 is verified after the semivariogram analysis, the inferred range of $\beta$ differs depending on Hurst and Hausdorff values. Thus, it should be necessary a direct estimation of $\beta$ by reviewing the power spectral density decay with $\omega$. (Figure 6 about here)

\subsection{Power- and Cross-power Spectral Densities}

The autocorrelation of SGR1 is shown in Figure 7a. Quite strong persistence (autocorrelation exceeding 0.6) is only detected for Landers and Hector Mine areas and, as expected, their autocorrelation patterns are very similar. Figure $7 \mathrm{~b}$ ascertains the power-law decay with $\omega$ (increase with the period), of the spectral density. Hypotheses concerning spectral contents for series SGR1 based for instance on white-noise or Markovian red-noise behavior should be discarded. Exponents $\beta$, exceeding 0.5 (Northridge) and slightly exceeding 1.0 (Landers and Hector Mine), suggest fGn models for simulating empiric SGR1 series. Nevertheless, it should be taken into account that this possibility is not in agreement with the range of Hausdorff measure. Thus, in spite of the confirmed self-affine character of SGR1 series, a model based on Gaussian noise series and the appropriate filtering process, characterized by the parameter $\beta$, of these series should be debatable. (Figures $7 \mathrm{a}, 7 \mathrm{~b}$, about here)

With respect to series SGR2, bearing in mind that they represent relatively short segments of background seismicity, results concerning Hausdorff measure derived from semivariograms would be questionable. Similarly, the computation of the power spectral density should be submitted to notable uncertainties. In consequence, only an approach to the self-affine character of SGR2 series could be achieved by taking into account that Hurst 
exponent values would be compatible with fGn series. Obviously, without confident results of $\beta$ and Ha exponents, this possibility is only a hypothesis.

The cross-correlation and cross-power spectral density for SGR1 corresponding to Landers, Northridge and Hector Mine aftershock areas are shown in Figures $7 \mathrm{c}$ and $7 \mathrm{~d}$. Cross-correlations are characterized by several peaks at different lags, depending on the pair of analyzed series. A notable feature is a common peak for a lag close to 90 months, which is approximately the elapsed time between Landers and Hector Mine mainshocks. This normalized peak is relatively small, except for the pair Landers-Hector Mine, for which it reaches a normalized value of 0.4. Pairs Landers-Northridge and Hector Mine -Northridge are also characterized by normalized peaks of 1.0 for lags close to 20 months, which is very approximately the elapsed time between Landers and Northridge mainshocks. The strong correlation between seismicity rates and a null time shift between Landers and Hector Mine aftershock areas is manifested by the normalized peak of 1.0 obtained for a null lag. After reviewing these common features, it looks like clear the close relationship between SGR1 series for Landers and Hector Mine. Given that aftershock areas of Landers and Hector Mine are almost coincident, it should be expected a close relationship between them. Nevertheless, the interaction between Northridge crisis and Landers and Hector Mine crises was not so expected, bearing in mind that a visual inspection of SGR1 series (Figure 2) does not suggest this kind of interaction. Cross-power spectral densities (Figure 7d) are characterized by a power-law behavior in terms of $\omega$ similar to that detected for power spectral densities. Once more, the strong correlation between the seismic activity of Landers and Hector Mine areas is underlined by the quite similar $\beta$ exponent for Landers-Northridge (0.83) and Hector MineNorthridge (0.84). The pair Hector Mine-Landers depicts a power-law decreasing of spectral 
density with an exponent $\beta$ (1.18) very similar to that obtained for the corresponding power spectral densities (1.19), suggesting again the strong similarity of these two seismic activities.

(Figures 7c, 7d about here)

\subsection{Statistical Modeling}

Another interesting point of view to characterize the background seismic activity is determining the best statistical model fitting empirical probabilities for SGR series. Given that the L-moments formulation offers a confident way of deciding which is the best statistical model by taking profit of the L-skewness-kurtosis diagrams, this formulation is chosen for the statistical analysis. Theoretical curves for generalized logistic, GLO, and Pearson-type III, PE3, accompanied by empiric L-skewness-kurtosis pairs for SGR1 and SGR2 are shown in Figure 8. Given that in most of cases the right model is GLO, all empirical SGR1 and assembled SGR2 series are finally fitted to this model. Figure 9a shows fits of SGR1 (including aftershock activity) to GLO model and Figure 9b fits of SGR2 (assembled segments of background activity) for Landers, Northridge and Hector Mine areas. Dashed lines represent Kolmogorov-Smirnov $95 \%$ uncertainty bands, with values estimated by the $\pm 1.36 / \mathrm{n}^{1 / 2}$ approach (Benjamin and Cornell, 1970) being $\mathrm{n}$ the number of SGR samples. Table 4 summarizes the values of GLO model parameters and the theoretical range of SGR. According to these values, only the location parameter $\xi$ does not remarkably change when the whole recording period (SGR1) or only assembled periods of background seismicity (SGR2) are considered. (Figures 8, 9a, 9b and Table 4 about here) (1)

Another question to be mentioned is the range of the argument $\triangle$ SGR of the GLO distribution. For series SGR1, generated by taking into account all the recording period, lower limits vary from 15.0 (Northridge) to 136.8 (Landers). These lower limits are closely related 
to the level of seismic activity of the different analyzed areas. It is also worth mentioning that

364 Landers aftershock area depicts an outstanding activity, even for periods without aftershock

365 activity. Hector Mine area shows lower activity and, finally, Northridge domain is characterized by a remarkable low level of seismicity. Obviously, these levels of seismic activity are notably reduced for assembled SGR2 series, being almost equal for Hector Mine and Northridge areas. Mention has to be made of the negative lower limit for Landers SGR2 series. After a close look at the corresponding plot (Figure 9b), it has to be assumed that this negative number is a computational artifact, instead of a wrong fit to GLO model, given that the cumulative distribution function for SGR2 equal to or lowering 90 events/month is only close to $1 \%$ of all SGR2 samples. Another question to review is the unrealistic upper limit of GLO distribution argument for all SGR series. Although an infinite value for any one of the SGR1 series has not physical meaning, the theoretical upper limit of GLO distribution should be simply assumed as an asymptotic value of real series. This fact is not so easy to justify for SGR2 series (Figure 9b), with empirical maximum values varying from 600 events/month (Landers) to 200 events/month (Northridge). In spite of this, given that the L-skewnesskurtosis diagrams and the Kolmogorov-Smirnov 95\% uncertainty bands confirm the goodness of fit of SGR2 empirical distributions to GLO model, the upper limit of the theoretical distribution for SGR2 has to be also assumed as an asymptotic value.

\section{DISCUSION OF THE RESULTS}

Two relevant patterns concerning background activity for the three aftershock areas can be observed in Figure 2. First, the achievement of stationary seismicity rates takes more than the assumed one-year span of aftershock activity. Second, this background seismicity stationary level is quite different previous to the mainshock and beyond the aftershock activity. Whereas for Landers and Northridge episodes the background activity is slightly 
higher after than before the seismic crisis, the level of seismic activity for Hector Mine is lower at the end of the crisis. Then, stress release processes along the aftershock sequences would generate states of stresses not necessarily equal to those related to previous seismic rates.

Another interesting feature is the spatial distribution of the seismicity before and after seismic crises, as well as the generation and persistence of nuclei of seismicity after a seismic crisis. An example is shown in Figure 3. Spatial patterns of seismic activity do not change until the triggering of Landers mainshock and the consequent aftershock activity. A belt of low seismic activity, previous to the mainshock, is strongly enhanced along the aftershock period and it persists, through the Hector Mine crisis, up to year 2007 (end of the analyzed period). Even more, Landers mainshock and its aftershock sequence could be one of the factors contributing to the triggering of Hector Mine mainshock. In other words, changes on stress field due to Landers crisis would have contributed to generate rupture of Hector Mine. This hypothesis would be in agreement with Parsons and Dreger (2000) and Felzer et al. (2002), who take into account seismotectonic arguments to also assume this hypothesis. Additionally, this interaction of the Landers crisis on the triggering of Hector Mine mainshock should be plausible taking into account the vicinity of both hypocenters. Nevertheless, as a counterpart, Northridge area is relatively close to Landers and Hector Mine areas (Figure 1) and effects of these crises on Northridge SGR1 curve (Figure2) and the spatial distribution of seismicity (Figure 4) are not detected. These contradictory examples of correlation and lack of correlation would be a consequence of the complex (fractal) distribution of faults, as well as of the heterogeneous distribution of tectonic stresses, both factors leading to a complex nonlinear mechanism governing the seismic activity and the stress propagation. 
The preceding discussion suggests that the seismic generation rate should be considered as a complex nonlinear system and that SGR series should be analyzed by means of fractal techniques. In agreement with this hypothesis, Hurst exponent and Hausdorff measure (together with time trend estimation), auto and cross-correlation, and parameter $\beta$ of the power and cross-power spectral densities offer a quite complete description of the complex mechanism of the seismicity. Hurst exponents manifest time persistence for periods of pure background seismicity and for the whole recording period, this fact being corroborated by some statistically significant trends, most of them negative. It is also worthy of mention that changes on Hurst exponent, always manifesting a persistent behaviour, seem to be partially conditioned by the evolution of stress fields along the background seismicity period before a mainshock and beyond the corresponding aftershock period. With respect to the significant time trends, it should be remembered the short time scale of the analysis (27 years) in comparison with length of seismotectonic processes. These trends could be a simple picture of short-time fluctuations on tectonic stress fields, but at the same time an interesting starting point for forecasting tools based on the persistence evidenced by the Hurst exponent. Additionally, Hausdorff measure derived from semivariograms verifies the self-affine character of SGR series for the whole recording period. Nevertheless, comparisons among H, Ha and $\beta$ do not permit assigning a specific model (derived from filtered Gaussian noise) to simulate SGR series. In spite of this, the power spectral density $S(\omega)$ proportional to $\omega^{-\beta}$, lags associated with the relative maxima of the autocorrelation function and Hurst exponents would be in agreement with models of SGR close to non-stationary long range persistence ( $\beta$ slightly exceeding 1.0) for Hector Mine and Landers areas. Northridge area, related to $\beta$ close to 0.5 , should be characterized by stationary weak long-range persistence. 
Another interesting question is the revision of lags related to maxima of crosscorrelation. Although a look at seismicity map time evolution does not permit to detect relationships between Northridge - Hector Mine and Northridge - Landers SGR1 series, some of these lags are very close to the elapsed times between the three mainshocks. Specifically, 442 the coincident main peaks of Landers - Northridge and Hector Mine - Northridge crosscorrelations would manifest the influence of Landers crisis on Northridge's. Similarly, the cross-correlation peak corresponding to the Landers - Hector Mine would approximately agree with the elapsed time between both mainshocks. Consequently, several signs point to underlying mechanism governing the seismicity of a certain area should depend partially on previous seismicity in neighboring areas.

Finally, the statistical analysis permits to verify that the theoretical distribution of monthly seismic generation rate does not depend on the area analyzed neither on the period considered, as the generalized logistic function, GLO, is the common distribution function model. Obviously, depending on the range of SGR series (background seismicity or the complete seismic activity), the scale, $\alpha$, and shape, $\kappa$, parameters of GLO distribution have different values. Nevertheless, the location parameter, $\xi$, does not distinguish between background seismicity (SGR2) and the complete seismic activity (SGR1).

\section{CONCLUSIONS}

An approach to the complex nonlinear mechanism of the seismicity has been achieved 459 by evaluating time series of seismic generation rate at monthly scale. The fractal analysis has 460 permitted to examine the whole 1981-2007 recording period, as well as segments of 
background seismicity. The effects of tectonic stress release after a mainshock on

462

neighbouring high-magnitude events have been empirically and qualitatively reviewed by looking closely at the spatial distribution of seismicity and cross-correlation and cross-power spectrum of SGR1. Notable time persistence (H clearly exceeding 0.5 ), corroborated by some statistically significant time trends, is also detected. SGR1 can be also defined as series with self-affine properties. Nevertheless, due to the different interpretation depending on pairs $(\mathrm{H}$, $\beta)$ and $(\mathrm{Ha}, \beta)$, it is not well resolved if these series could be interpreted as the result of filtered Gaussian noise.

(1)

0

Some characteristics related to SGR1 series, as the Hurst exponent, time trends on the background seismicity, stress levels before and after a seismic crisis and the time evolution of SGR1 series close to a seismic crisis, could be considered as possible predictive signs of forthcoming seismic crises. Whereas the results indicate that this inference seems to be plausible for Landers crisis, it is not so clear for Northridge crisis. For Hector Mine, this hypothesis can be assumed with some uncertainty because the results are influenced by the spatial vicinity of Landers crisis.

.

Finally, it should be mentioned that other fractal techniques could be applied, as those based on the reconstruction theorem, which would contribute to validate the complexity of the physical mechanism of the seismicity, loss of memory of the process, chaotic behaviour and predictive instability. Nevertheless, one of the shortcomings of the reconstruction theorem should be remembered: among other constraints, confident results are based on long series. Even the whole 1981-2007 recording period does not generate long enough monthly series. As a counterpart, longer SGR series could be easily generated at shorter time scales. Nevertheless, it is debatable that these shorter time scales could be appropriate for a right 
description of seismic rates, especially for cases such as Northridge area, where the seismic activity, excepting along the aftershock period, is not very intense.

ACKNOWLEDGEMENTS: This research was supported by the Spanish Government through the project CGL2015-65913-P.

\section{REFERENCES}

Benjamin, J.R. and Cornell, C.A., 1970, Probability, statistics and decision for civil engineering. McGraw-Hill, New York, 685 pp.

Bottiglieri, M. Lippiello, E., Godano, C. and de Arcangelis, L., 2009, Identification and spatiotemporal organization of aftershocks. Journal of Geophysical Research, 114, B03303.

Brune, J.N., Biasi, G., Ludwig, L.G. and Rood, D.H., 2010, Assumed background seismicity as a partial explanation for discrepancies between precariously balanced rocks and 2008 California hazard maps. AAPG Pacific Section Meeting, (Abstract) Anaheim, California, May 19, p. 27.

Cao, T., Petersen, M.D. and Reichle, M.S., 1996, Seismic hazard estimate from background seismicity in Southern California. Bulletin of the Seismological Society of America, 86, 1372-1381.

Console, R., Jackson, D.D., Kagan, Y.Y., 2010, Using the ETAS model for catalog declustering and seismic background assessment. Pure and Applied Geophysics, 167, 819830.

Diks, C., 1999, Nonlinear time series analysis. Methods and applications. World Scientific, New York, 207 pp.

Eneva, M. and Pavlis, G.R., 1991, Spatial distribution of aftershocks and background seismicity in Southern California. Pure and Applied Geophysics, 137, 35-61. 
Felzer, K.R., Becker, T.W., Abercrombie, R.E., Ekström, G. and Rice, J.R., 2002, Triggering of the 1999 MW 7.1 Hector Mine earthquake by aftershocks of the 1992 MW 7.3 Landers earthquake. Journal of Geophysical Research 107, doi: 10.1029/2001JB000911.

Goltz, C., 1997,. Fractal and chaotic properties of earthquakes. LectureNotes in Earth sciences, 77. Springer, Berlin, 178 pp.

Habermann, R.E. and Wyss, M., 1984, Background seismicity rates and precursory seismic quiescence: Imperial valley, California. Bulletin of the Seismological Society of America, 74, 1743-1755.

Hauksson, E., 2010, Spatial separation of large earthquakes, aftershocks and background seismicity: analysis of interseismic and coseismic seismicity patterns in Southern California. Pure and Applied Geophysics, 167, 979-9.

Hosking, J.R.M. and Wallis, J.R., 2005, Regionsal frequency analysis. An approach based on L-moments. Cambridge University press, Cambridge, 224 pp.

Kagan, Y.Y., 2002, Aftershock zone scaling. Bulletin of the Seismological Society of America, 92, 641-655.

Korvin, G., 1992, Fractal modes in the Earth sciences. Elsevier science publishers, Amsterdam, 396 pp.

Kunkel, K.E., Andsager, K. and Easterling, D.R., 1999, Long term trends in extreme precipitation events over Uni,ed States and Canada. Journal of Climate, 12, 2515-2527.

Lana, X. and Burgueño, A., 2000, Statistical distribution and spectral analysis of rainfall anomalies for Barcelona (NE Spain). Theoretical and Applied Climatology, 66, 211-228.

Lana, X., Martínez, M.D., Serra, C. and Burgueño, A., 2005, Periodicities and irregularities of indices describing the daily pluviometric regime of the Fabra Observatory (NE Spain) for the years 1917-1999. Theoretical and Apllied Climatology, 82, 183-198. 
544 Malamud, B.D. and Turcotte, D.L., 1999, Self-affine time series: I. generation and analyses. Advances in Geophysics, 40. R. Domowska and V. Saltzman (Edit.), Academic Press, 90 pp.

Mandelbrot, B.B. and Wallis, J.R., 1969, Computer experiments with fractional Gaussian noises, Parts I, II , III. Water Resources Research, 5, 228-267.

Michael, A.J and Jones, L.M., 1998, Seismicity alert probabilities at Parkfield, California, revisited. Bulletin of the Seismological Society of America, 88, 117-130.

Mitchell, J.M., Dzerdzeevskii, B., Flohn, H.,Hofmeyr, W.L., Lamb, H.H., Rao, K.N. and Wallén, C.C., 1996, Climatic change. Technical note 79. World Meteorological 553 Organization, Geneve, 79 pp.

Myers, S.C. and Walter, W.R., 1999, Using epicenter location to differentiate events from natural background seismicity. Proceedings of the $21^{\text {st }}$ Research symposium: Technologies for monitoring the comprehensive nuclear-test-ban treaty. Las Vegas, Nevada, September 2124, www.osti.gov/scitech/biblio/14543.

Parsons, T. and Dreger, D.S., 2000, Static-stress impact of the 1992 Landers earthquake sequence on nucleation and slip at the site of the $1999 \mathrm{M}=7.1$ Hector Mine earthquake, southern California. Geophysical Research Letters, 27, 1949-1952.

Serra, C., Burgueño, A., Martínez, M.D. and Lana, X ., 2006, Trends of dray spell across 564 Catalonia (NE Spain) for the second half of the $20^{\text {th }}$ century. Theoretical and Applied Climatology, 85, 165-183.

Shcherbakov, R., Turcotte, D.L and Rundle, J.B., 2005, Aftershock statistics. In: Statistical 567 Seismology. Editors: Vere-Jones, D., Ben-Zion, Y. and Zúñiga, R. Pure and Applied 568 Geophysics, 162, 1051-1076.

569 Shcherbakov, R., van Aalsburg, J., Rundle, and Turcotte, D.L., 2006, Correlations in aftershock and seismicity patterns. Tectonophysics, 413, 53-62. WMO, Geneva, 192 pp. 
574 Van Stiphout, T., Schorlemmer, D. and Wiemer, S., 2011, The effect of uncertainties on 575 estimates of background seismicity rate. Bulletin of the Seismological Society of America, $576101,482-494$.

577 Toda, S., Stein, R.S., Richards-Dinger, K. and Bozkurt, S., 2005, Forecasting the evolution of 578 seismicity in Southern California: Animations built on earthquake stress transfer. Journal of 579 Geophysical Research, 110, B05S16.

580

581 Turcotte, D.L., 1997, Fractal and chaos in geology and geophysics (2 ${ }^{\text {nd }}$ edition). Cambridge 582 University Press, Cambridge, 398 pp.

583

584 Woessner, J. and Wiemer, S., 2005, Assessing the quality of the earthquake catalogue: 585 estimating the magnitude of completeness and its uncertainty. Bulletin of the Seismological 586 Society of America, 95(2), 684-698.

587

588 Zhang, X., Zwiers, F.W. and LI, G., 2004, Monte Carlo experiments on the detection of 589 trends in extreme values. Journal of Climate, 17, 1945-1952. 


\section{List of Figures}

Figure 1. a) Geographical SCSN network domain. b) Epicenters of earthquakes along the 1981-2007 recording period with local magnitudes $\geq 4.5$. c) Guternberg-Richter law for the three catalogues associated with the three aftershock areas and the whole 19812007 recording period.

Figure 2. SGR1 series for the afterhock areas of Landers (a), Northridge (b) and Hector Mine (c). More detailed plots are included for time intervals corresponding to a few years before and after mainshock events.

Figure 3. Spatial distribution of epicenters in Hector Mine aftershock area for seven sequential time periods, distinguishing background seismicity from aftershock activity.

Figure 4. Spatial distribution of epicenters in Northridge aftershock area for three sequential periods, distinguishing background from aftershock seismic activities.

Figure 5. Rescaled analysis for the three aftershock areas. Analysed series SGR1 include all the 1981-2007 recording period.

Figure 6. Semivariograms for SGR1 series, including aftershock episodes.

Figure 7. a) Autocorrelation for series SGR1. b) Power spectral density for series SGR1. c) Cross-correlation between Landers and Northridge, Hector Mine and Landers and Hector Mine and Northridge SGR1 series. d) Cross-power spectral density for Landers and Northridge, Hector Mine and Landers and Hector Mine and Northridge SGR1 series.

Figure 8. L-skewness-kurtosis diagram for generalized logistic, GLO, and Pearson-type III, PE-3, models. Acronyms LND, NOR and HM design SGR1 series for the whole recording period. $\mathrm{LNDb}, \mathrm{NORb}$ and $\mathrm{HMb}$ correspond to assembled series, SGR2, of background seismic rate for the three aftershock areas.

Figure 9. Statistical distribution of SGR1 and SGR2 series for a) the whole recording period and b) assembled periods of background activity. 
a)

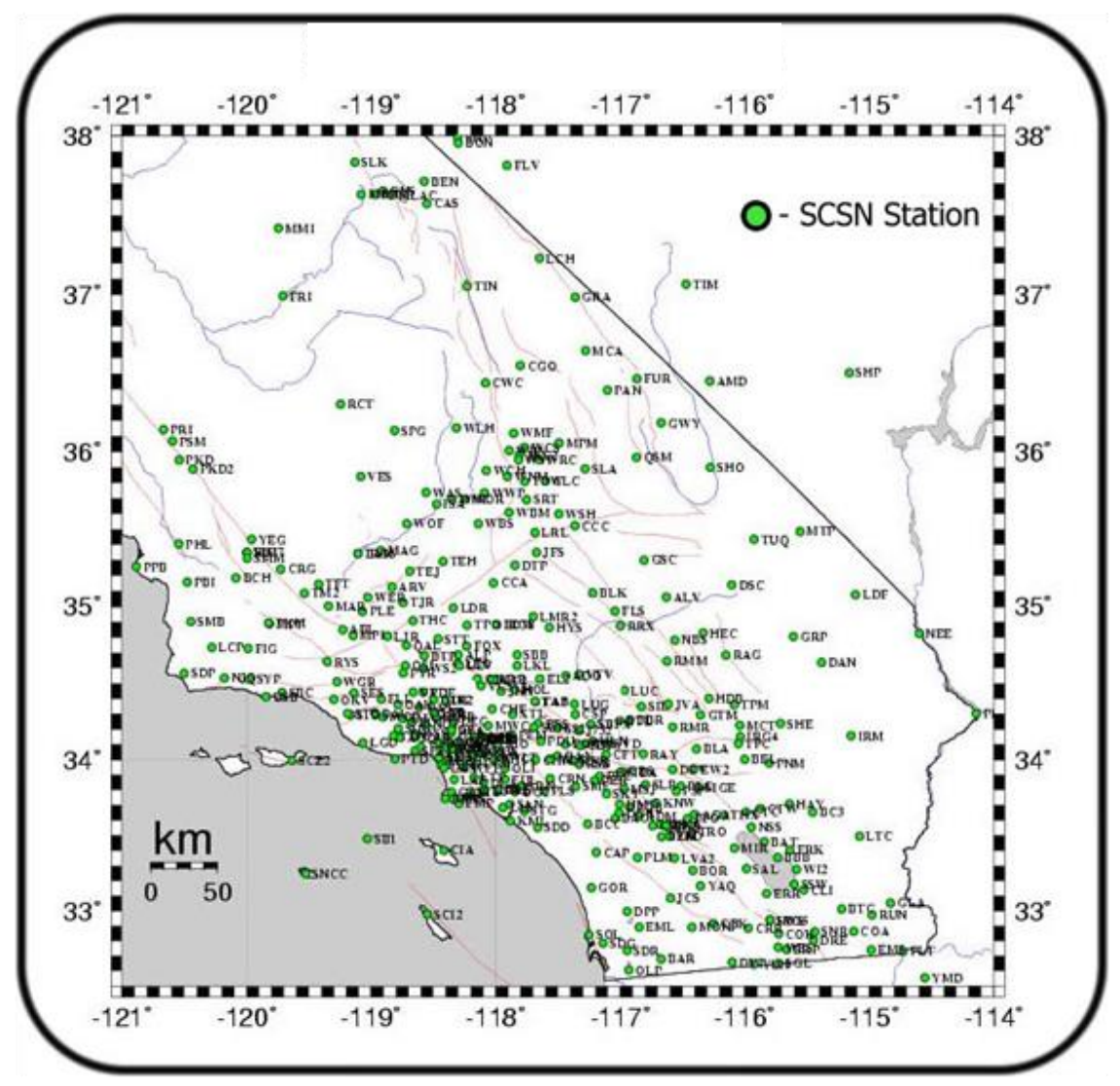

b)
$4.0<\mathrm{m}<4.5$ 口
$4.5<\mathrm{m}<5.0$
$5.0<m<5.5$
$5.5<\mathrm{m}<6.0$
$6.0<\mathrm{m}<6.5$
$\mathrm{m}>6.5$

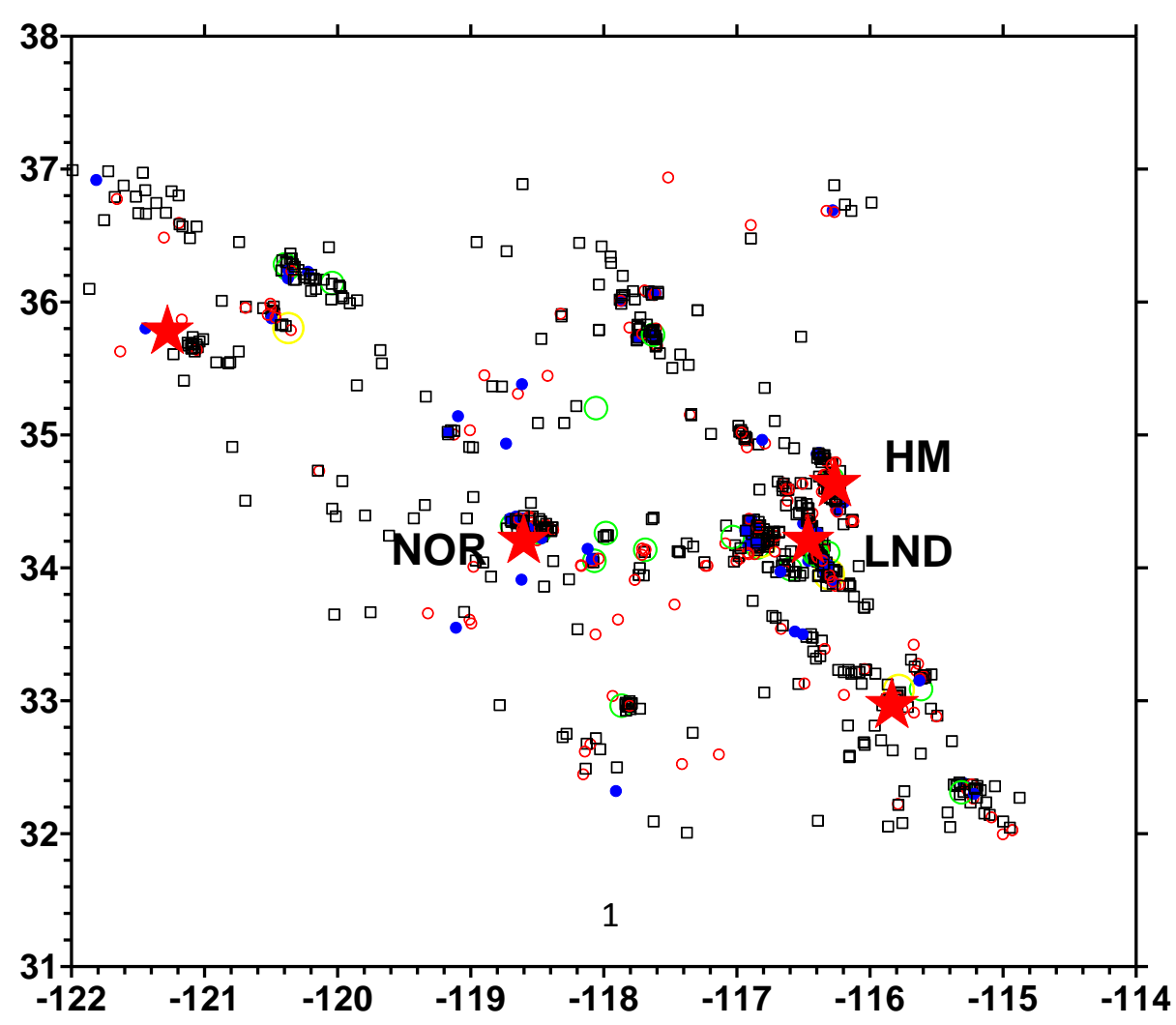


c)
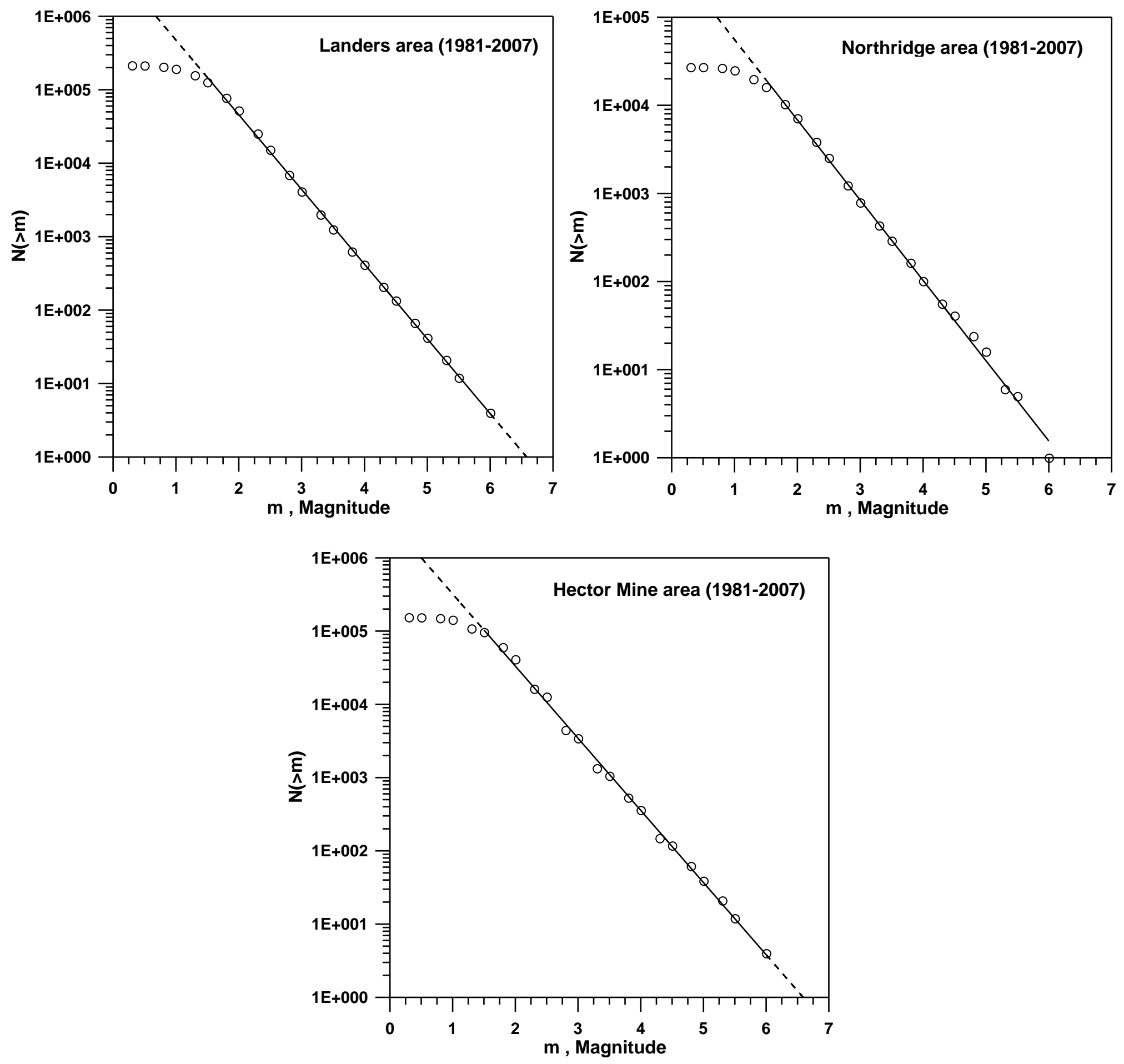

Figure 1 
a)

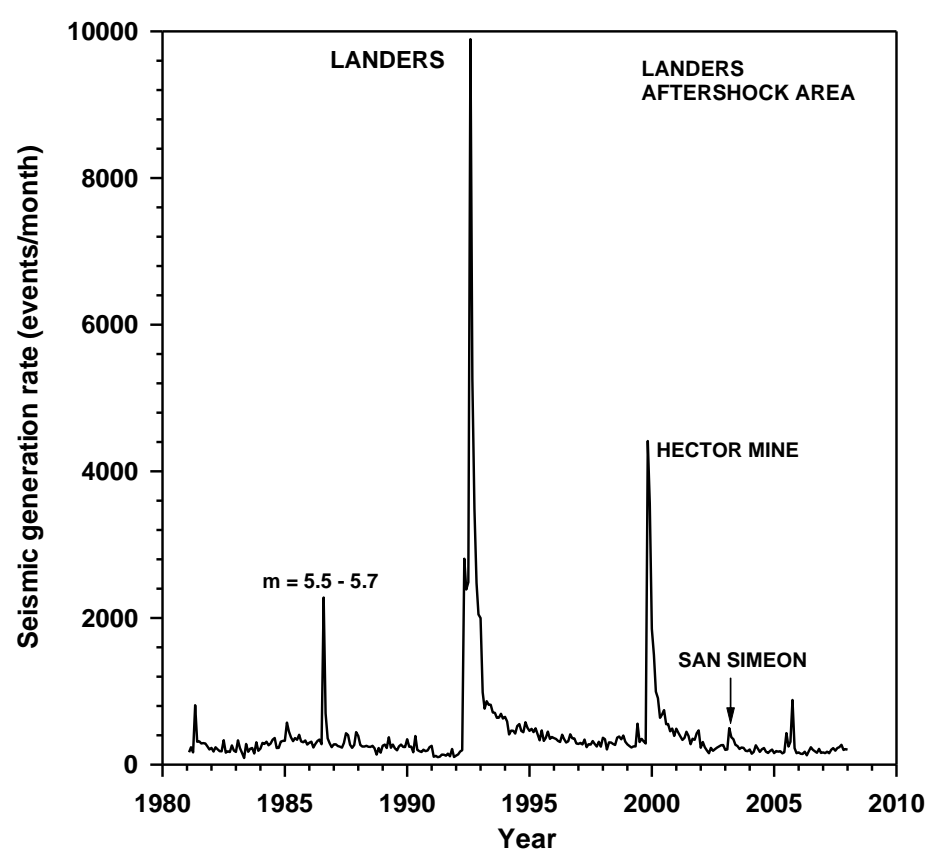

b)

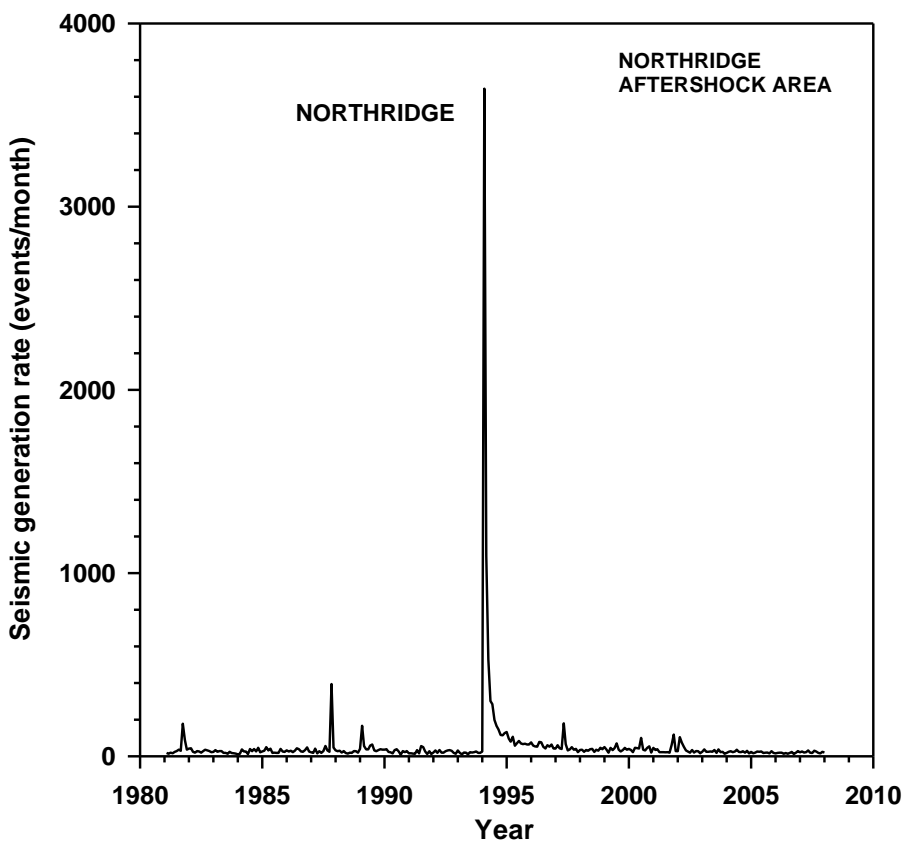

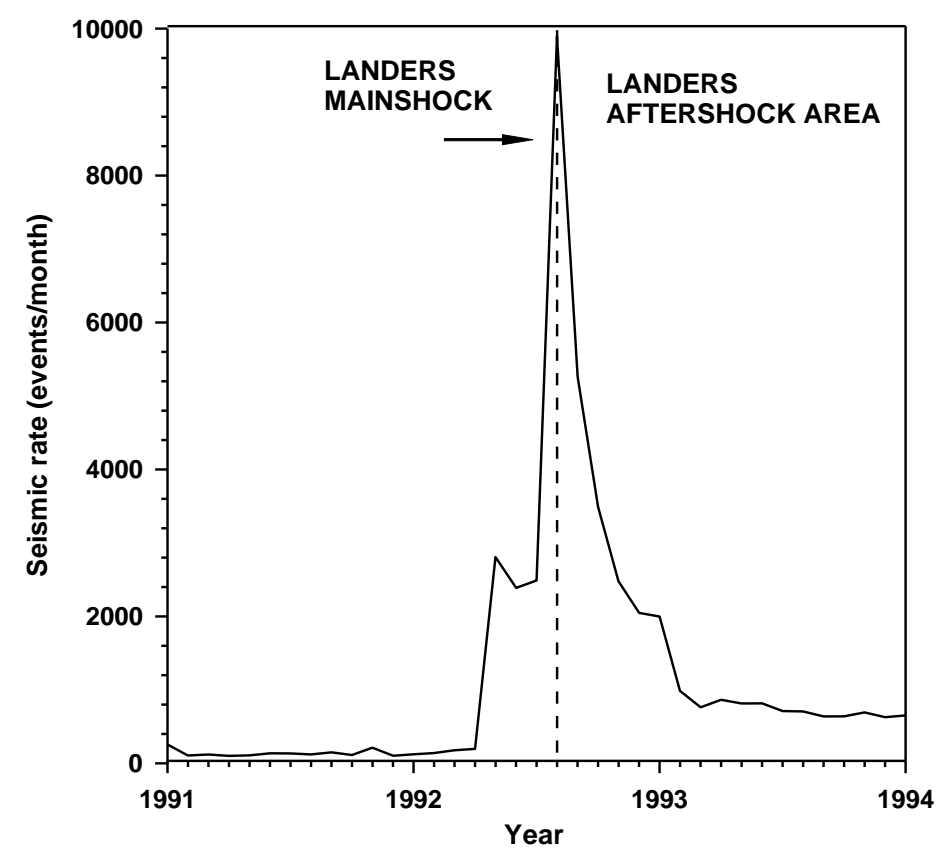

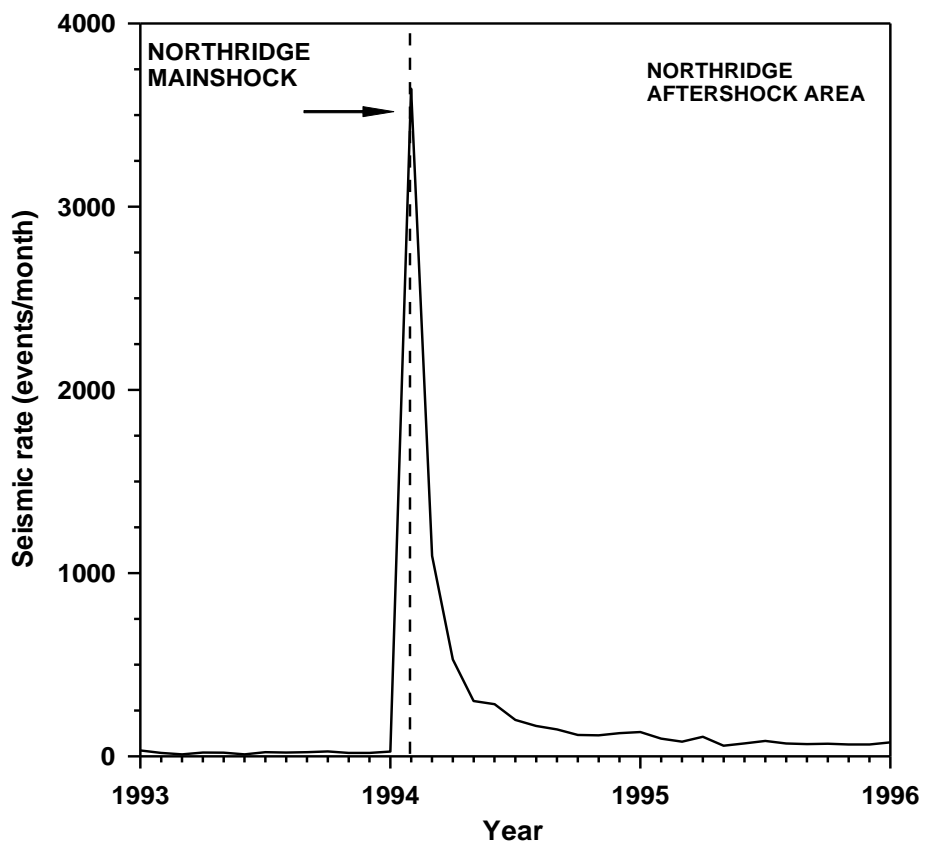


c)

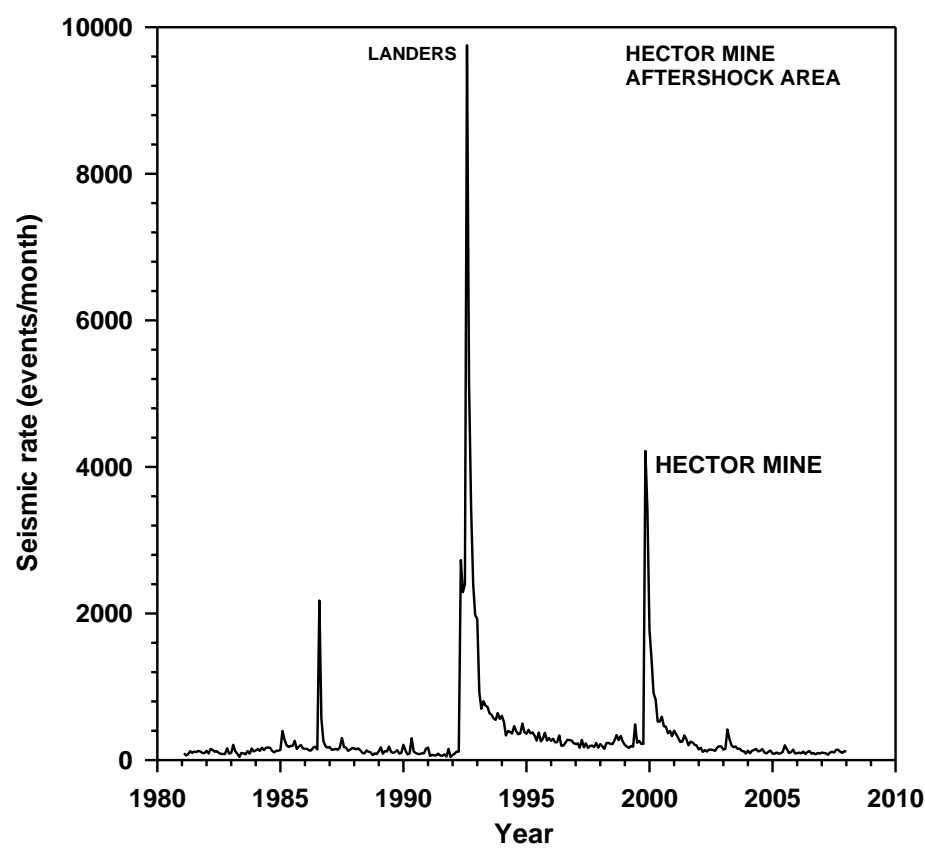

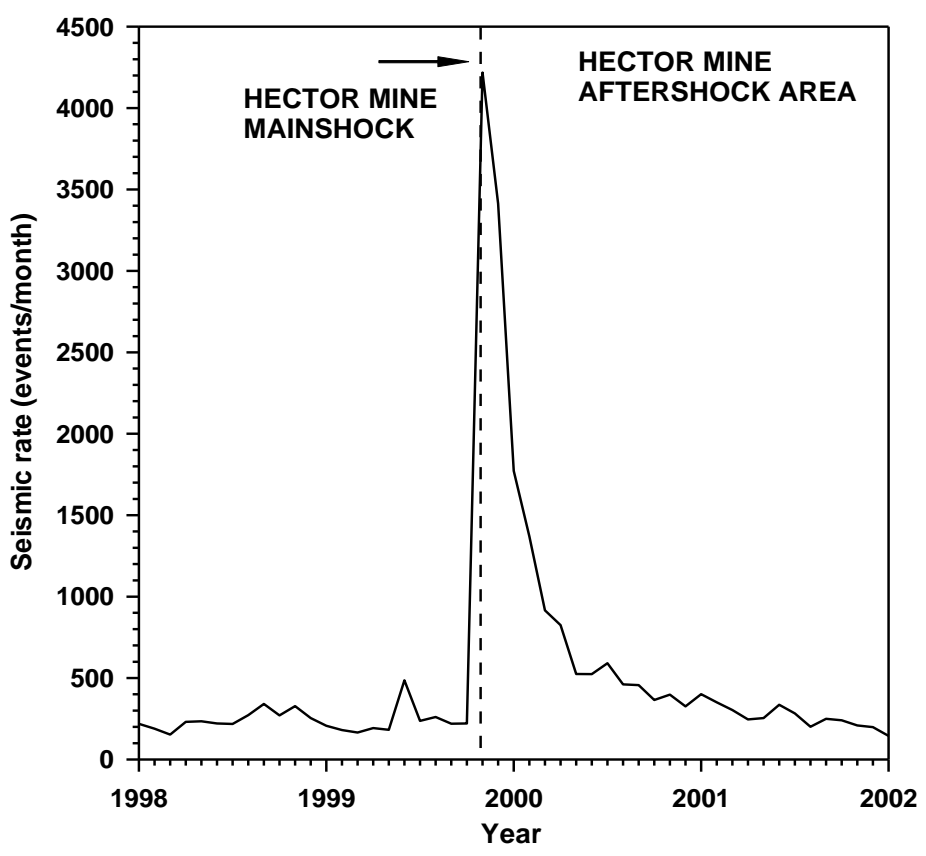

Figure 2. 

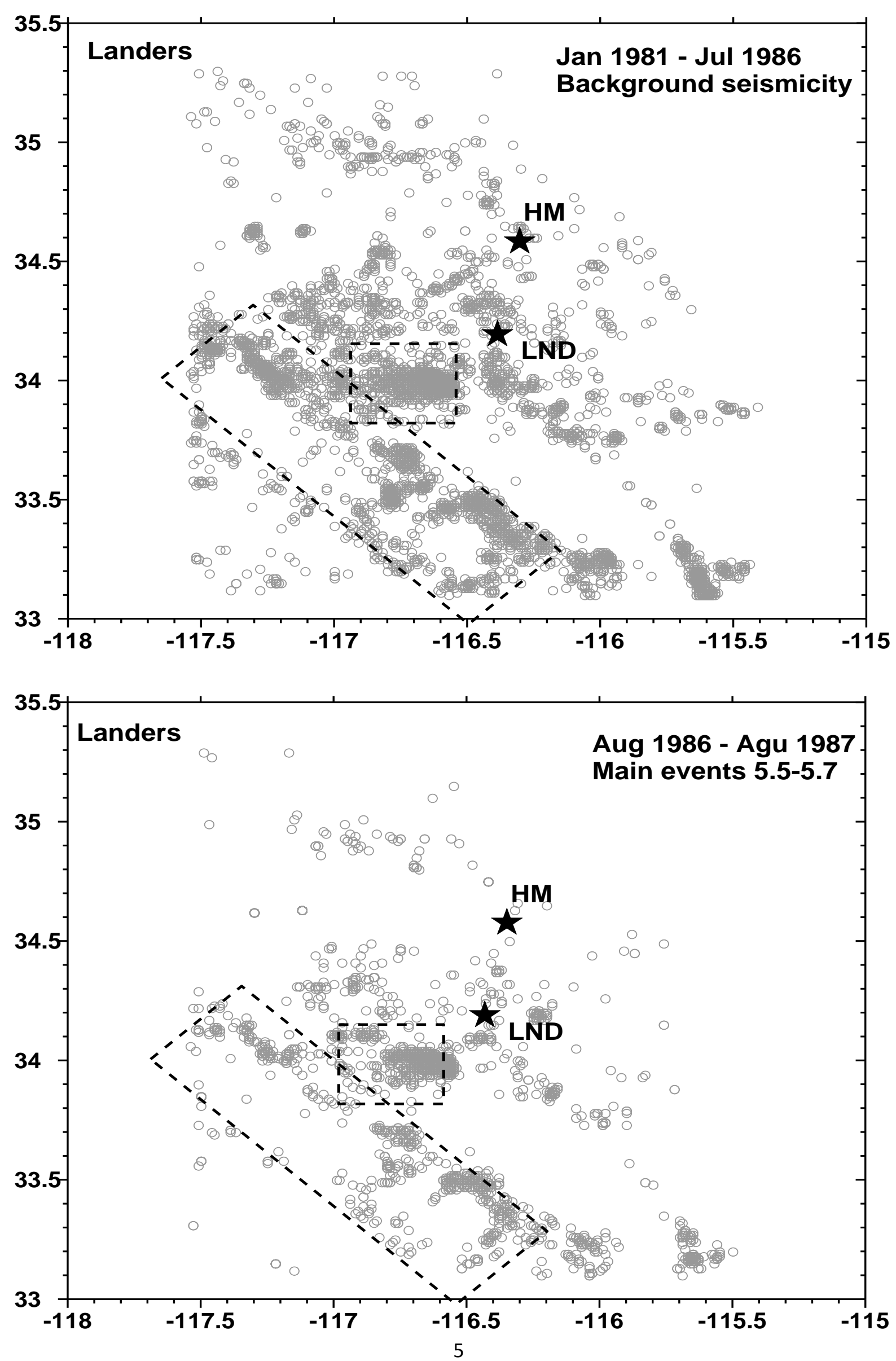

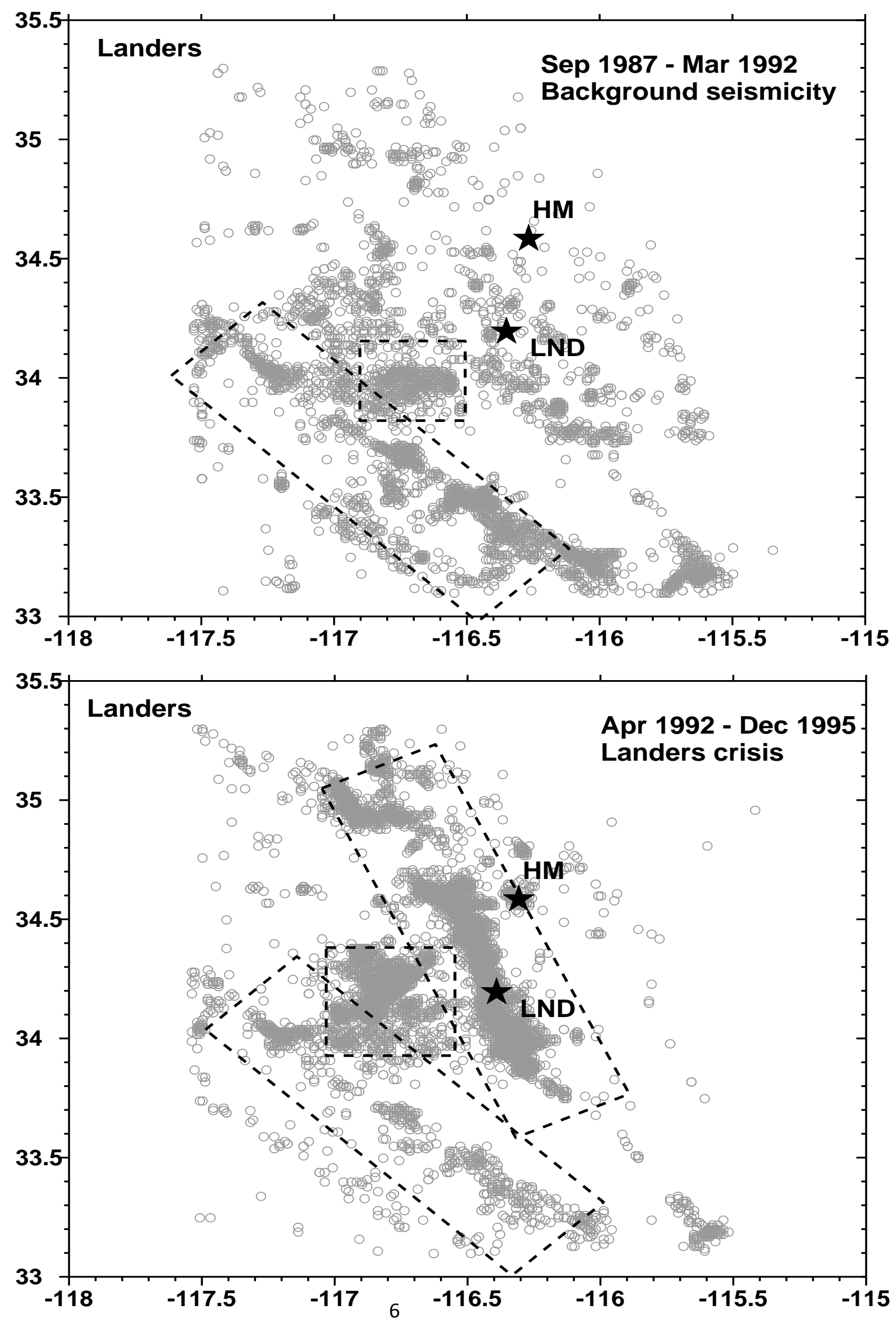

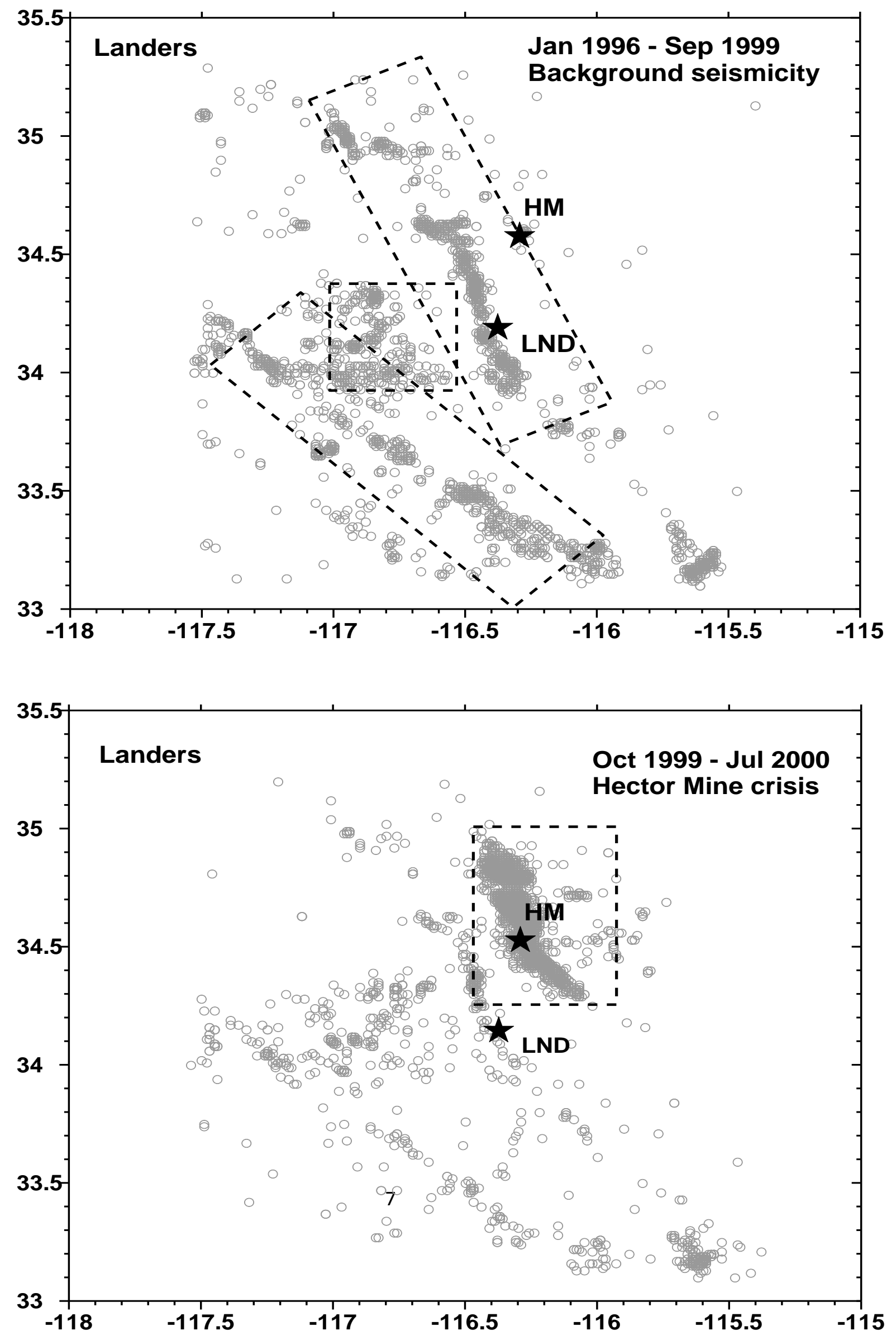


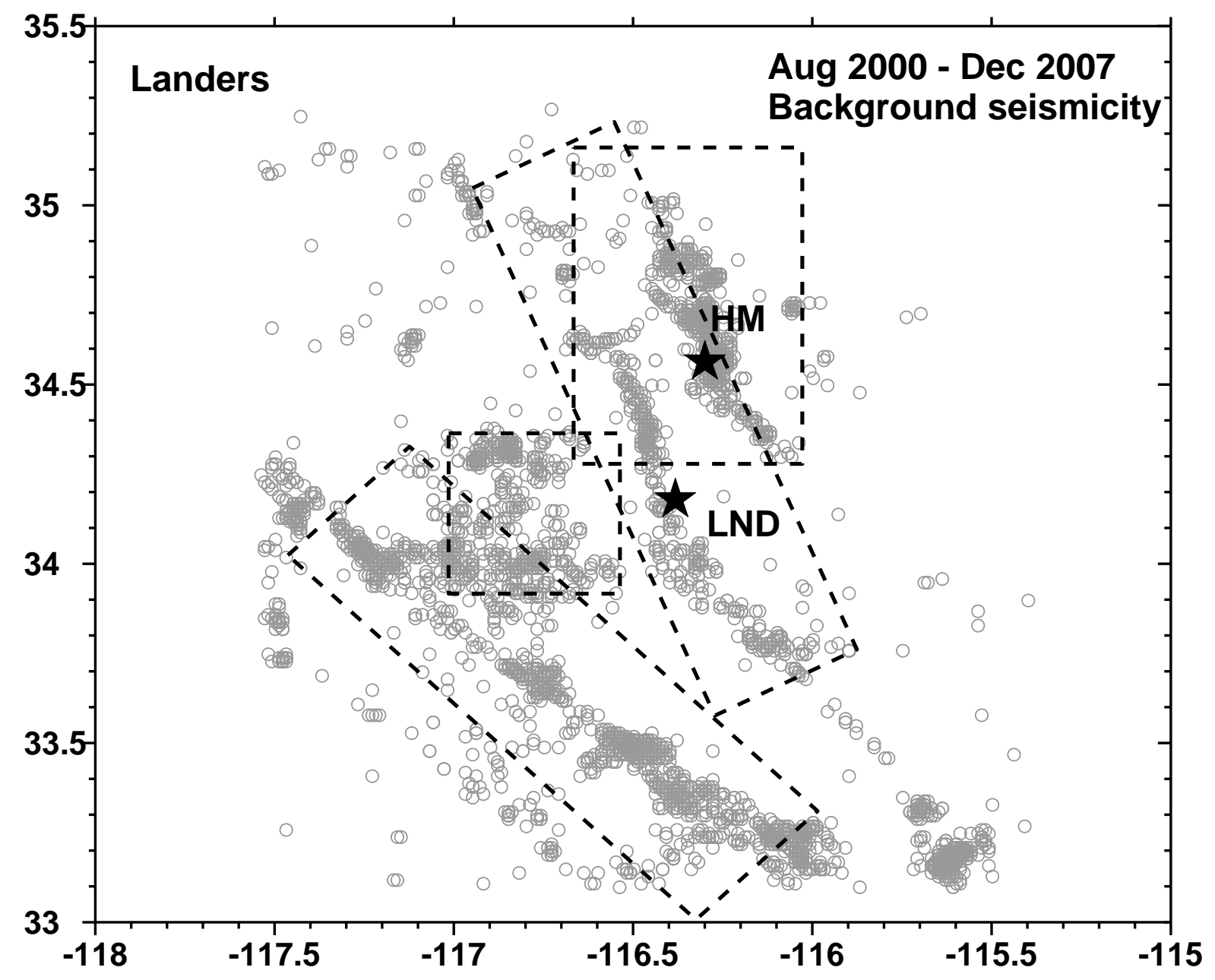

Figure 3 

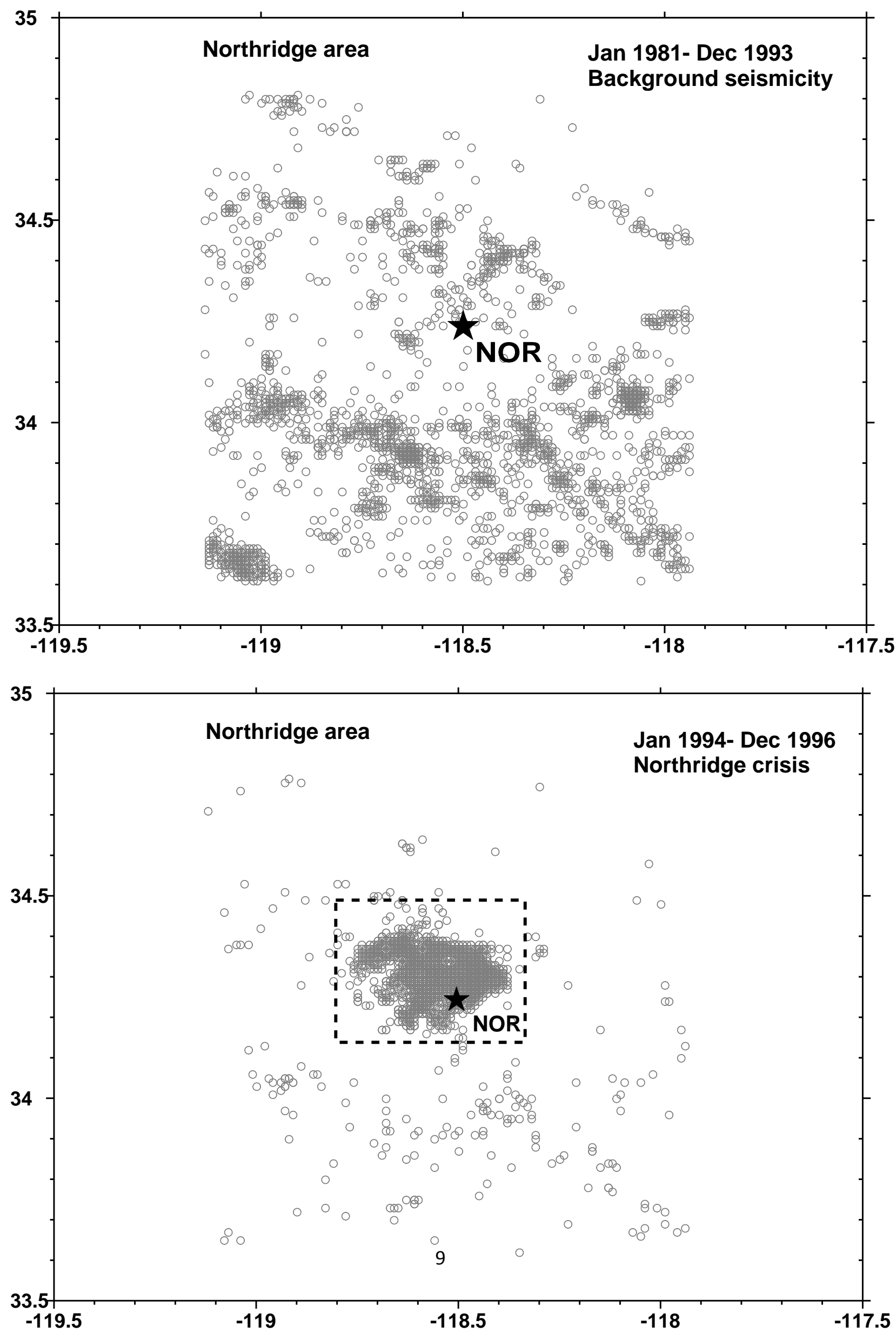


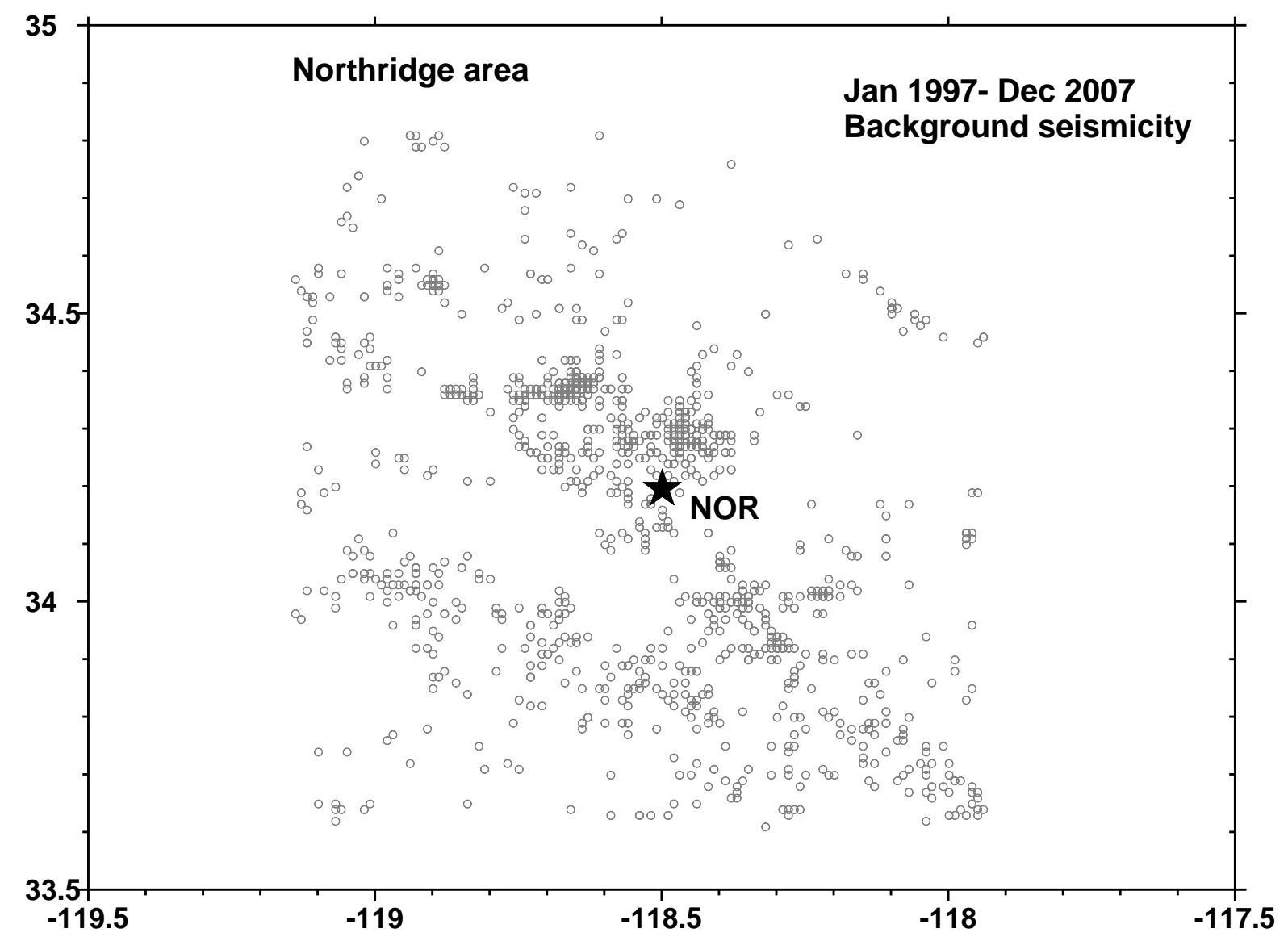

Figure 4. 

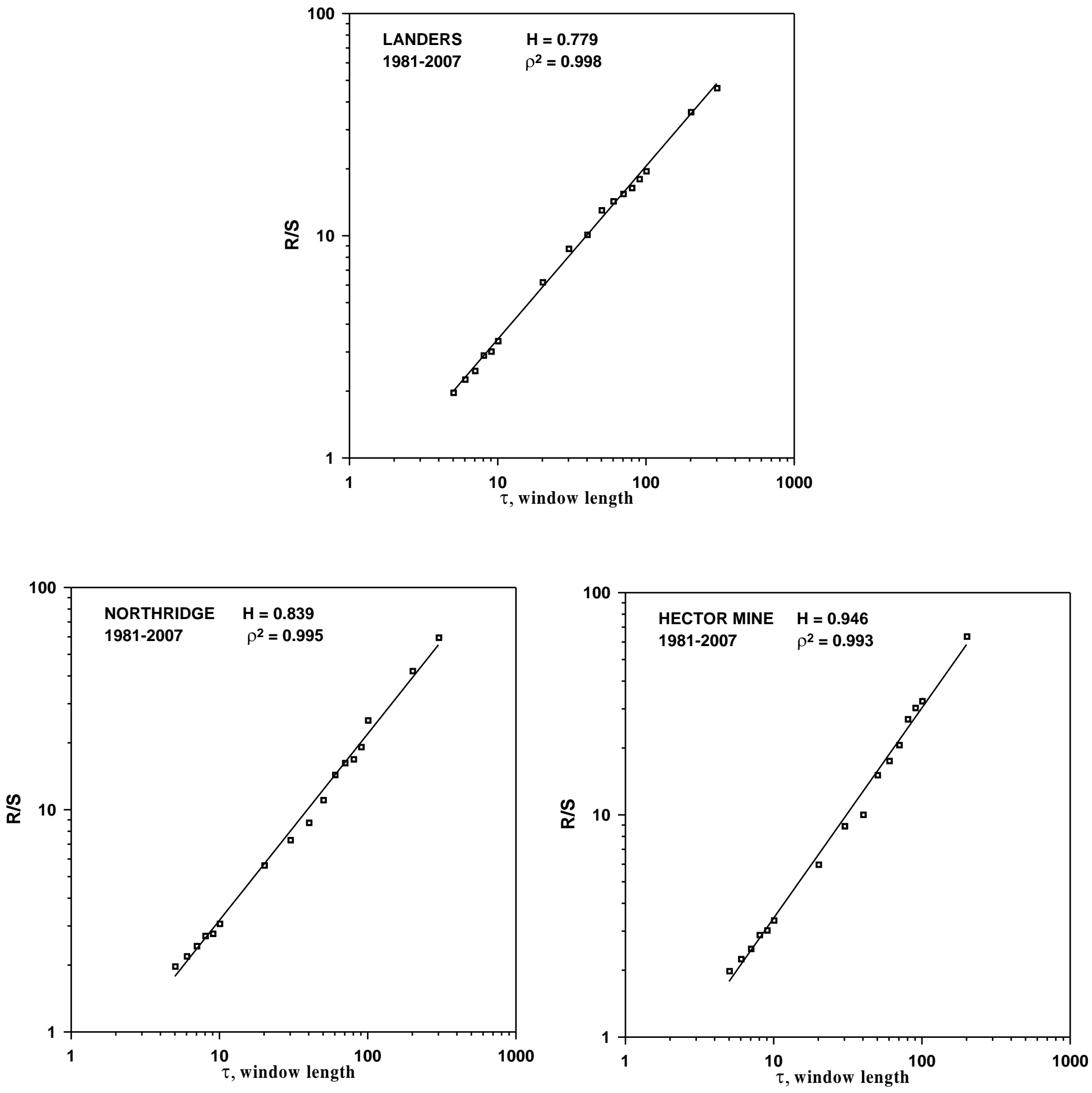

Figure 5 

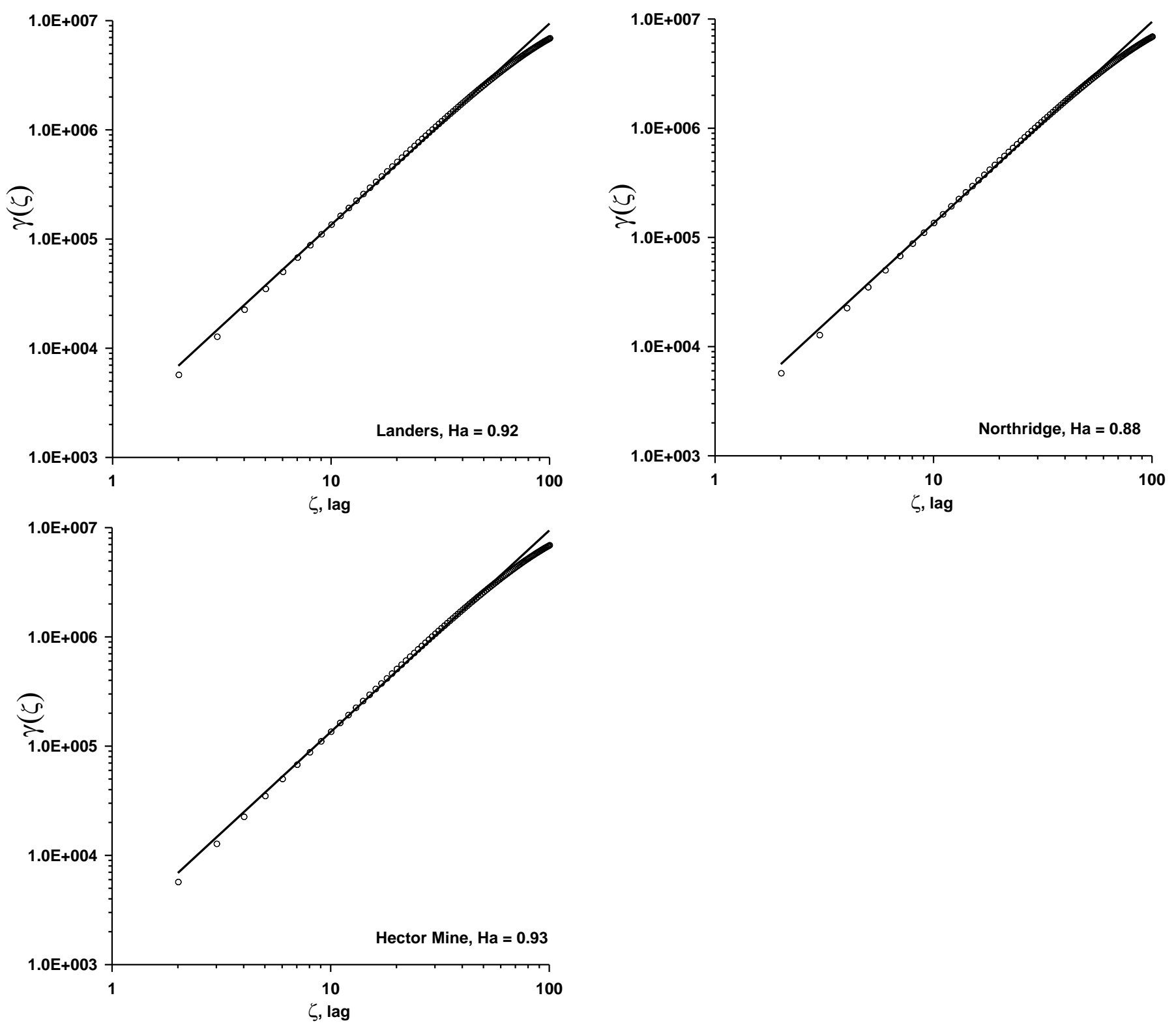

Figure 6. 
a)
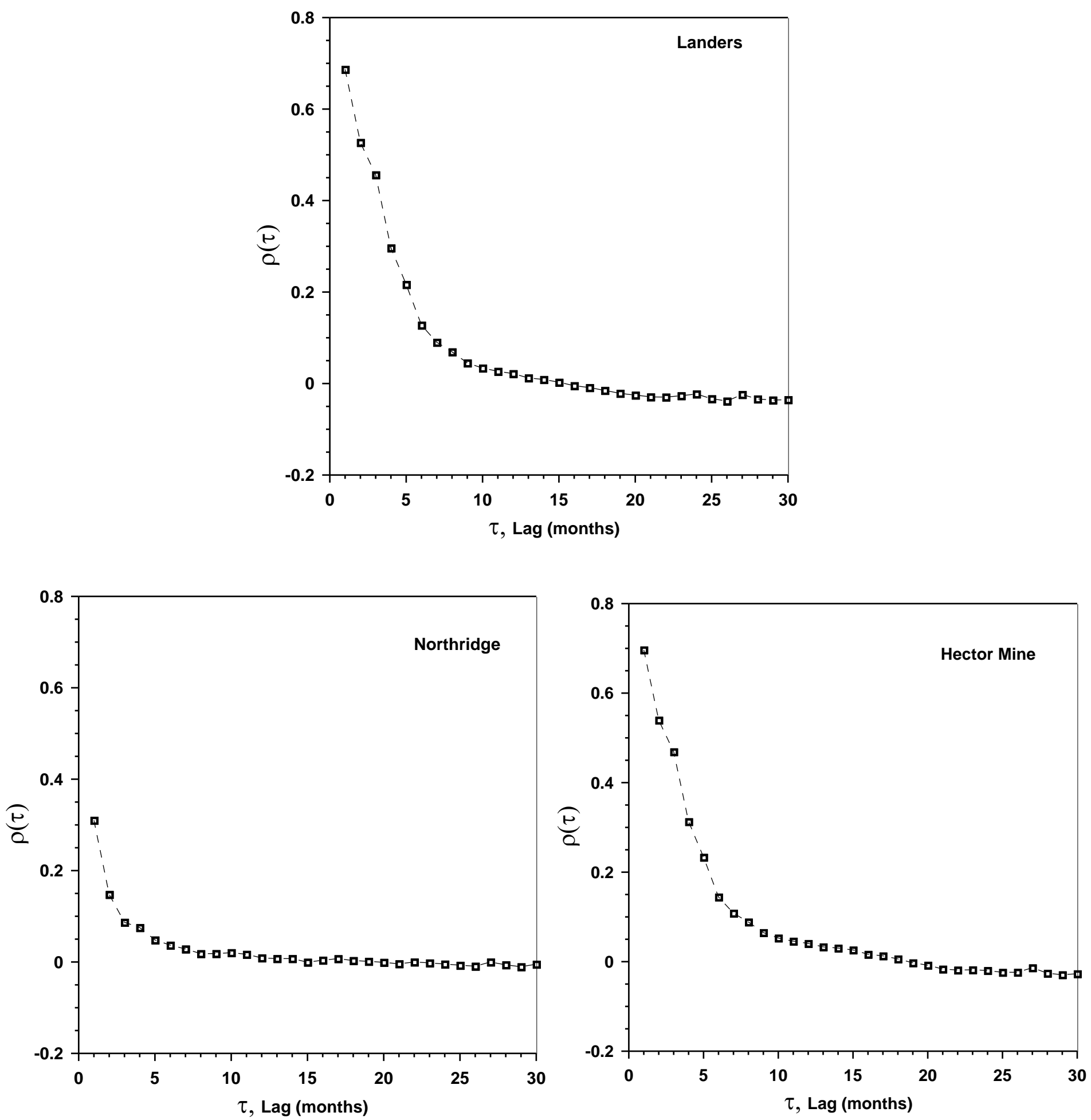
b)
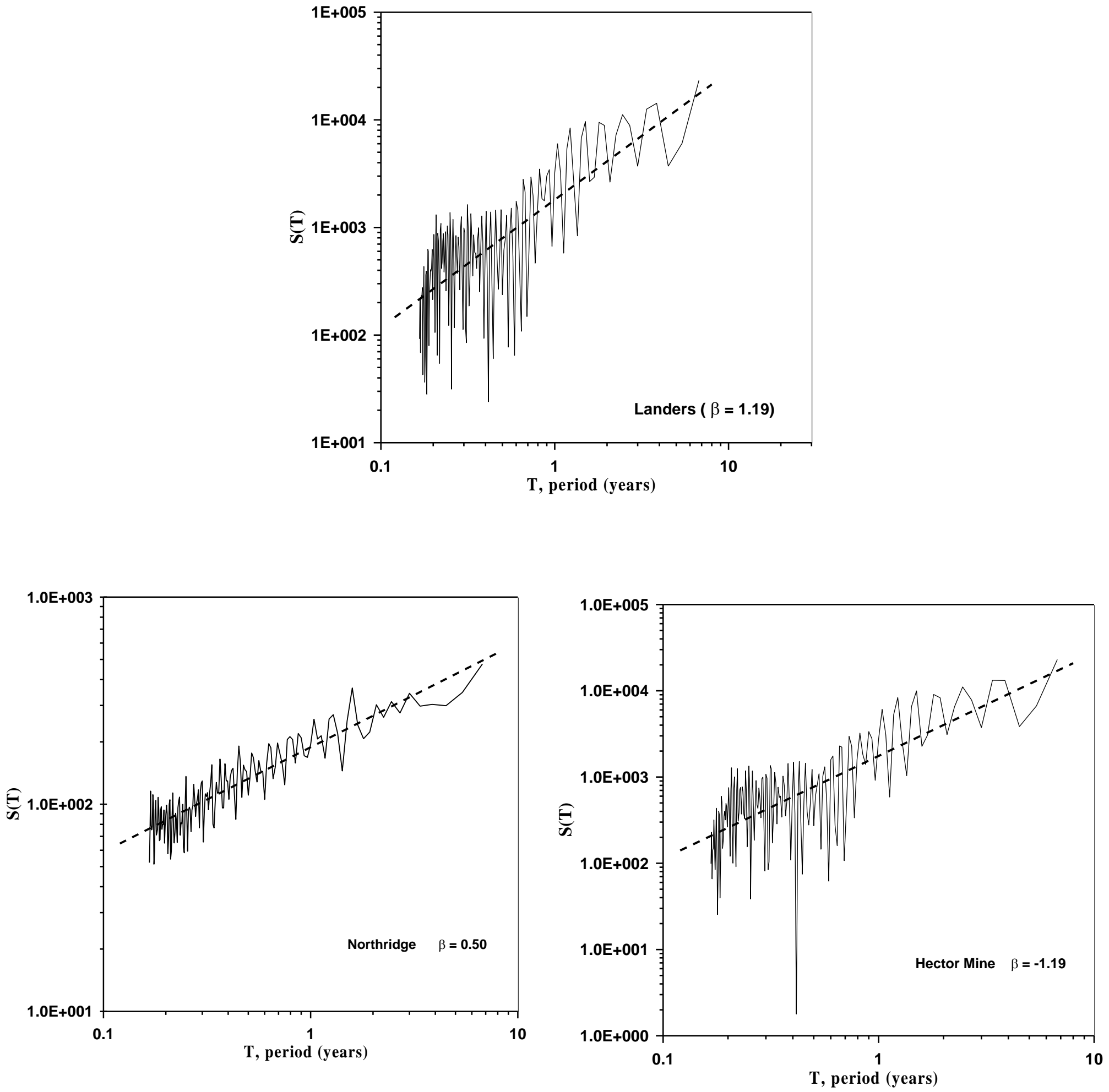

c) 

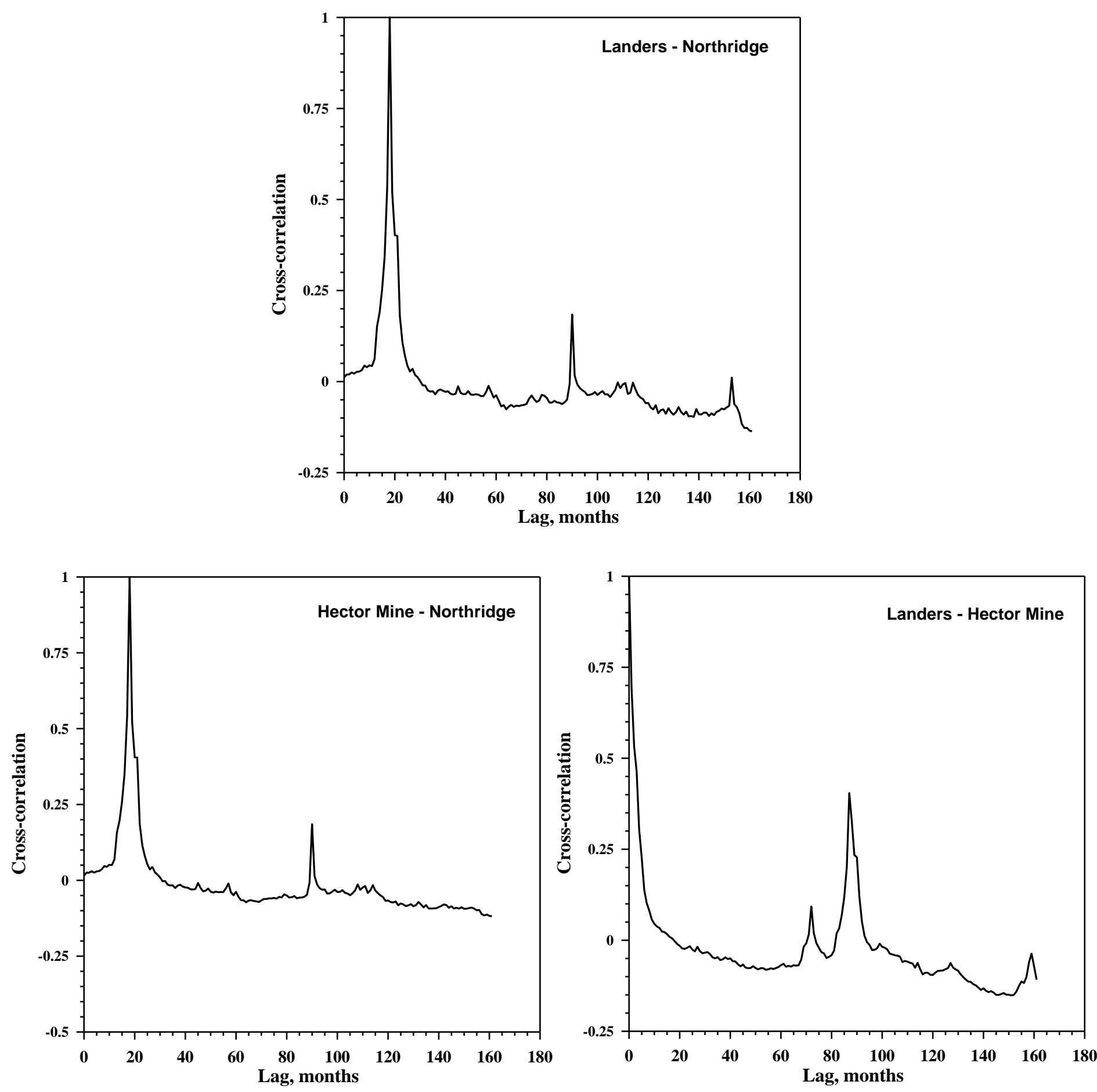
d)
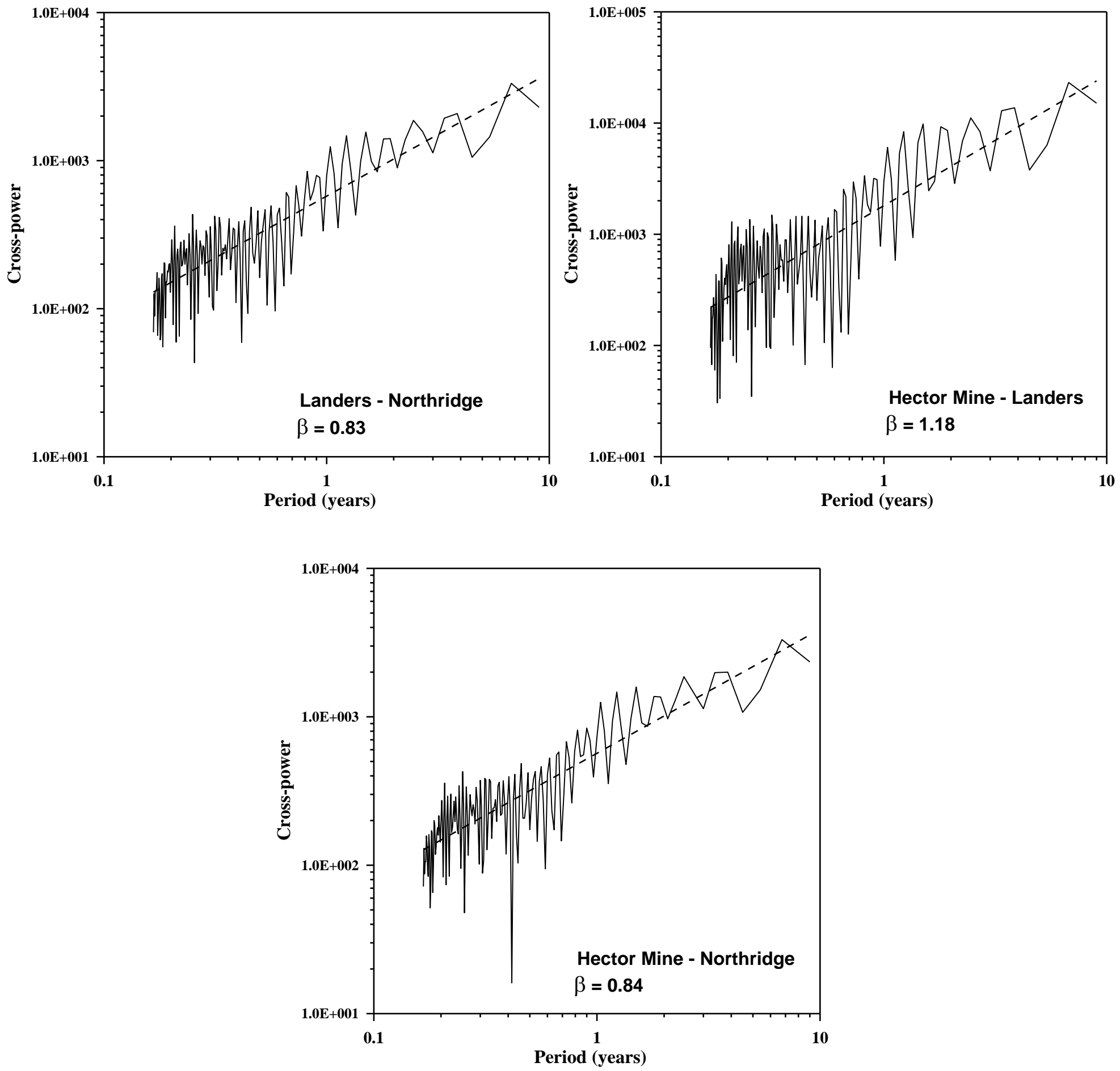

Figure 7. 


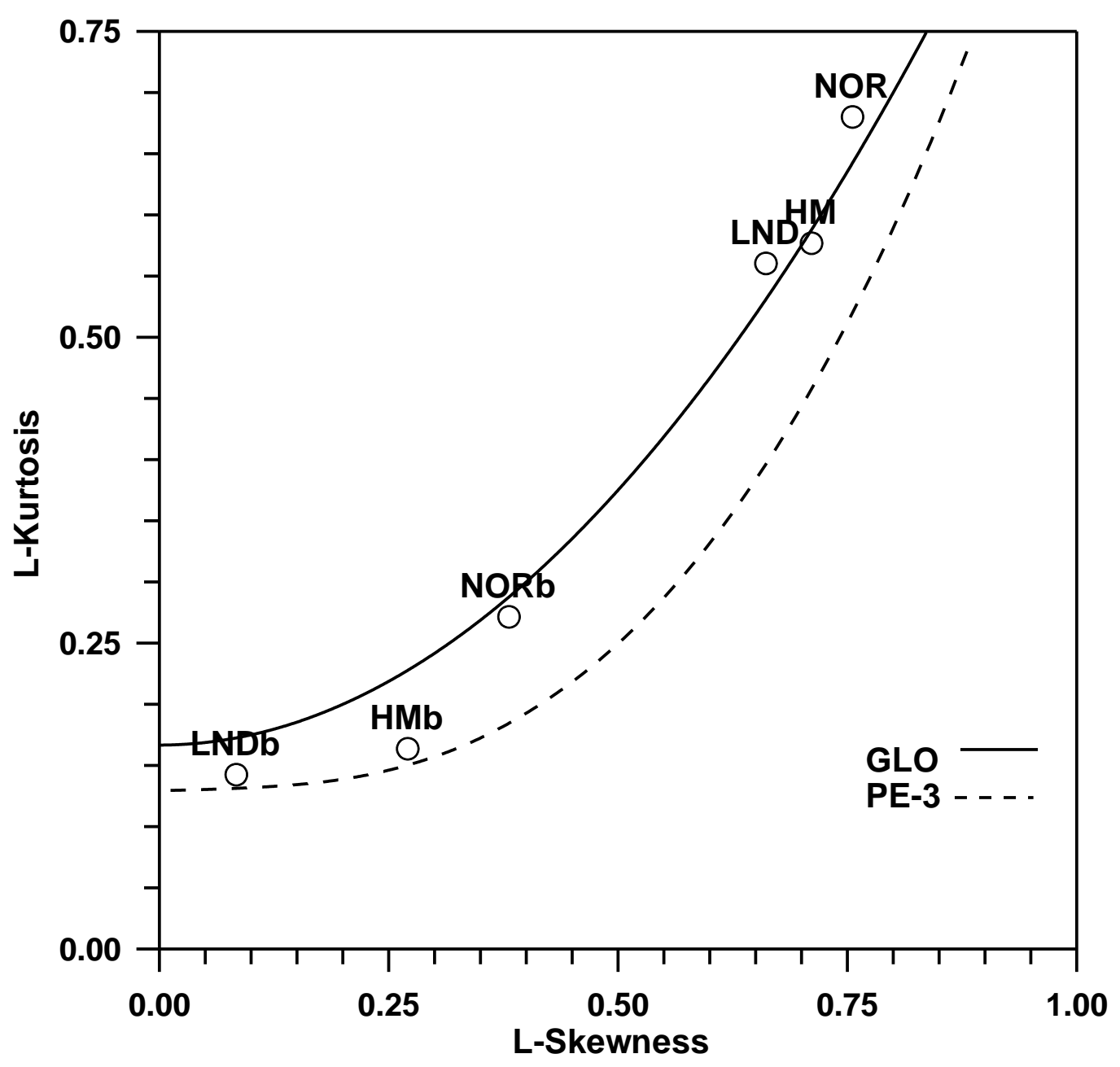

Figure 8 
a)
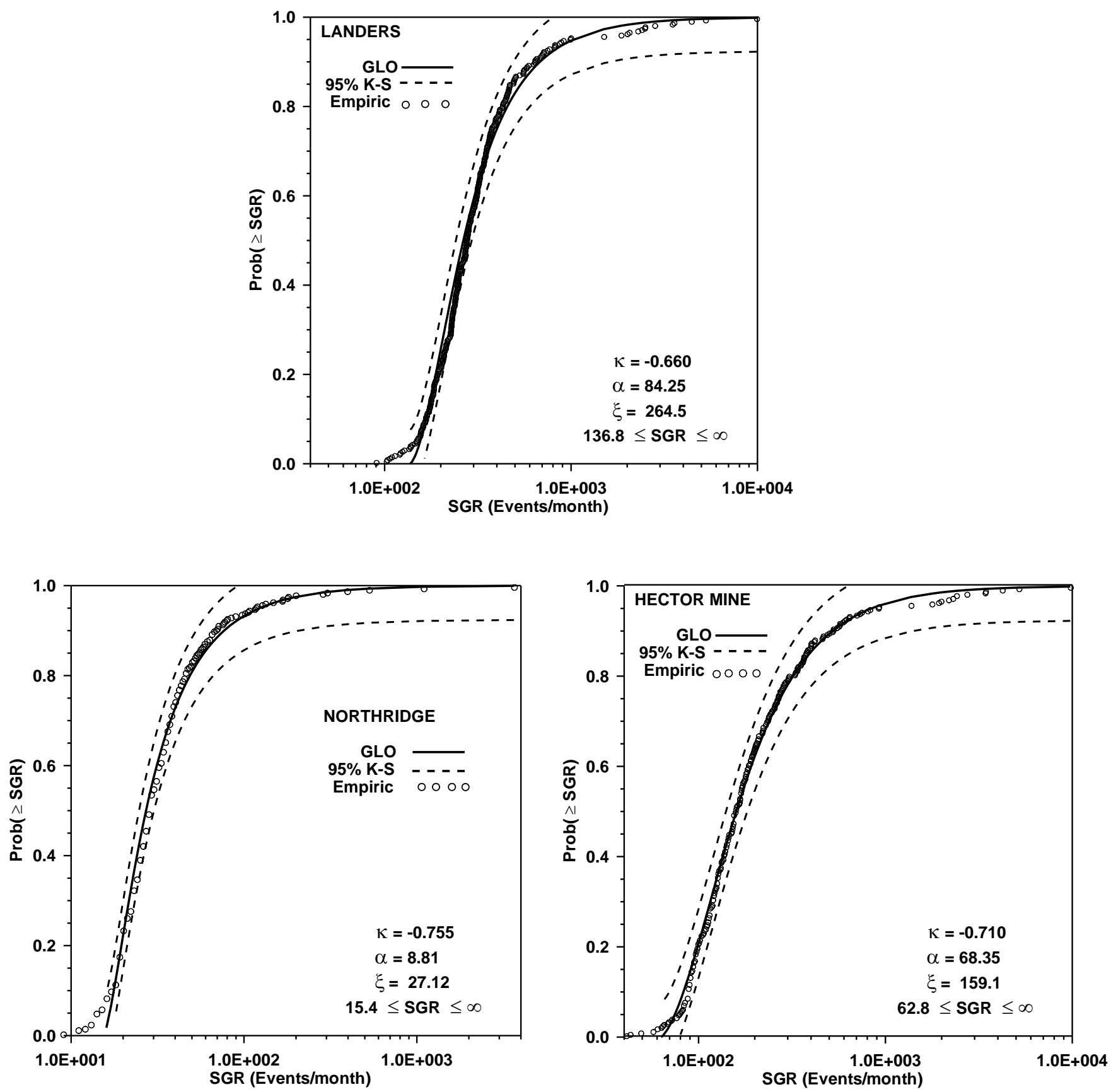
b)
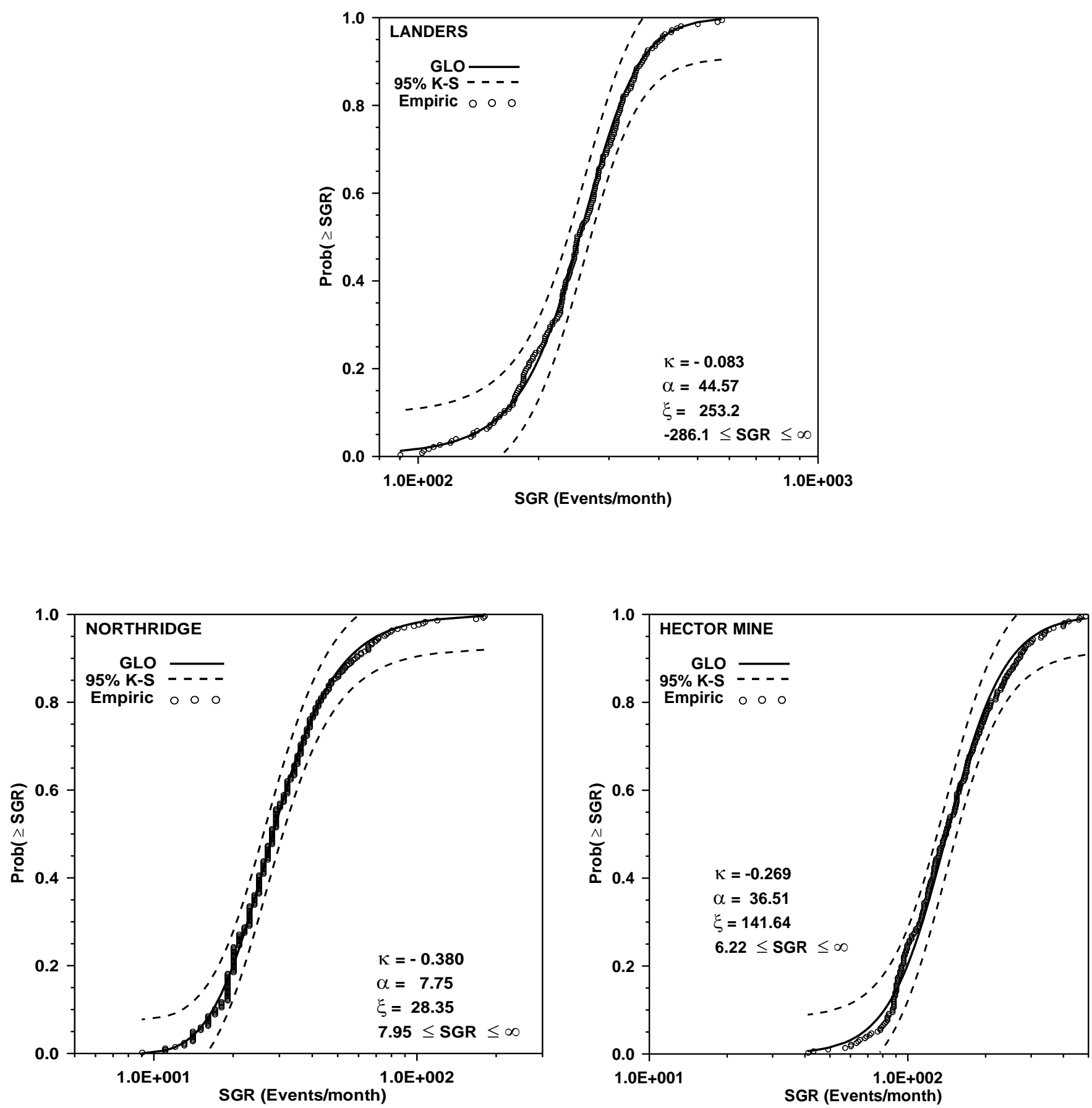

Figure 9. 
Table 1. Local magnitude, m; latitude, $\theta$; longitude, $\lambda$; date, length, $L$ (days) of the aftershock activity; minimum magnitude, $\mathrm{m}_{\min }$, assuring catalogue completeness; $\mathrm{b}$ parameter of the G-R law; number of aftershocks, $\mathrm{N}_{\mathrm{A}}$, equaling to or exceeding magnitude $\mathrm{m}_{\min }$, and aftershock area, given in degrees of latitude and longitude around the epicenter.

\begin{tabular}{lccccccccc}
\hline & $\mathbf{m}$ & $\boldsymbol{\theta}\left({ }^{\mathbf{0}} \mathbf{N}\right)$ & $\boldsymbol{\lambda}\left({ }^{\mathbf{0}} \mathbf{W}\right)$ & $\mathbf{D a t e}$ & $\mathbf{L}$ & $\mathbf{m}_{\text {min }}$ & $\mathbf{B}$ & $\mathbf{N}_{\mathbf{A}}$ & Area \\
\hline Landers & 7.3 & $34: 12.00$ & $116: 26.22$ & $06 / 28 / 1992$ & 365 & 2.0 & $0.98 \pm 0.02$ & 20649 & $1.1^{0} \times 1.1^{0}$ \\
\hline Northridge & 6.7 & $34: 12.78$ & $118: 32.22$ & $01 / 17 / 1994$ & 365 & 2.0 & $0.91 \pm 0.02$ & 5979 & $0.6^{0} \times 0.6^{0}$ \\
\hline Hector Mine & 7.1 & $34: 35.64$ & $116: 16.26$ & $10 / 16 / 1999$ & 365 & 2.0 & $1.01 \pm 0.01$ & 12334 & $1.0^{0} \times 1.0^{0}$ \\
\hline
\end{tabular}


Table 2. Values of Hurst exponent, $\mathrm{H}$, for the three aftershock areas and several background activity periods.

\begin{tabular}{cccccc}
\hline \multicolumn{2}{c}{ Landers } & \multicolumn{2}{c}{ Northridge } & \multicolumn{2}{c}{ Hector Mine } \\
\hline Years & H & Years & H & Years & H \\
\hline $1981-86$ & 0.93 & $1981-87$ & 0.67 & $1981-86$ & 0.78 \\
\hline $1987-92$ & 0.82 & $1988-94$ & 0.73 & $1987-92$ & 0.83 \\
\hline $1996-99$ & 0.78 & $1995-07$ & 0.88 & $1996-99$ & 0.83 \\
\hline $2002-07$ & 0.75 & & & $2002-07$ & 0.96 \\
\cline { 1 - 1 }
\end{tabular}


Table 3. Significant time trend, Slp, in events/month, and Mann-Kendall statistic, Emk for segments of background seismicity (SGR2 series). Non-significant trends are not listed.

\begin{tabular}{ccccccccc}
\hline \multicolumn{3}{c}{ Landers } & \multicolumn{3}{c}{ Northridge } & \multicolumn{3}{c}{ Hector Mine } \\
\hline Years & Slp & Emk & Years & Slp & Emk & Years & Slp & Emk \\
\hline $1981-86$ & 1.8 & 3.5 & $1981-87$ & ---- & ---- & $1981-86$ & 1.3 & 5.2 \\
\hline $1987-92$ & -2.4 & -6.0 & $1988-94$ & - & -3.4 & $1987-92$ & -1.6 & -5.8 \\
& & & & 0.17 & & & & \\
\hline $1996-99$ & ---- & ---- & $1995-07$ & - & -10.8 & $1996-99$ & ---- & --- \\
& & & & 0.26 & & & & \\
\hline $2002-07$ & -1.3 & -2.3 & & & & & & \\
\cline { 1 - 1 }
\end{tabular}


Table 4. Location, scale and shape parameters, $\xi, \alpha$ and $\kappa$, of the GLO distribution and range of SGR for a) the whole recording period, SGR1, and b) assembled segments, SGR2, of background activity.

\begin{tabular}{|c|c|c|c|c|c|c|c|c|c|}
\hline 1981-2007 (a) & $\xi$ & $\alpha$ & $\kappa$ & ASGR & $\begin{array}{l}\text { Background } \\
\text { Seismicity }{ }^{(b)}\end{array}$ & $\xi$ & $\alpha$ & $\mathbf{K}$ & $\Delta$ SGR \\
\hline Landers & 264.5 & 84.25 & -0.66 & $136.8, \infty$ & Landers & 253.2 & 44.57 & -0.08 & $-286.1, \infty$ \\
\hline Northridge & 27.1 & 8.81 & -0.78 & $15.4, \infty$ & Northridge & 28.35 & 7.75 & -0.38 & $7.9, \infty$ \\
\hline Hector Mine & 159.1 & 60.35 & $\begin{array}{l}-0.71 \\
\end{array}$ & $62.8, \infty$ & Hector Mine & 141.6 & 36.51 & -0.27 & $6.2, \infty$ \\
\hline
\end{tabular}

